\title{
Container Terminal Berth and Yard Collaborative Allocation for Import and Export Synchronous Operations by Computational Logistics
}

\author{
Bin Li $\left(\mathbb{D},{ }^{1}\right.$ Xiong Jiang $\mathbb{D}^{1},{ }^{2}$ and Junhan Lei ${ }^{2}{ }^{2}$ \\ ${ }^{1}$ School of Mechanical and Automotive Engineering, Fujian University of Technology, Fuzhou 350118, China \\ ${ }^{2}$ School of Transportation, Fujian University of Technology, Fuzhou 350118, China \\ Correspondence should be addressed to Bin Li; mse2007_lb@whut.edu.cn
}

Received 3 November 2021; Accepted 21 December 2021; Published 1 February 2022

Academic Editor: Tingsong Wang

Copyright (C) $2022 \mathrm{Bin} \mathrm{Li} \mathrm{et} \mathrm{al.} \mathrm{This} \mathrm{is} \mathrm{an} \mathrm{open} \mathrm{access} \mathrm{article} \mathrm{distributed} \mathrm{under} \mathrm{the} \mathrm{Creative} \mathrm{Commons} \mathrm{Attribution} \mathrm{License,} \mathrm{which}$ permits unrestricted use, distribution, and reproduction in any medium, provided the original work is properly cited.

Container terminal operators have practical and clear requirements on improving operational efficiency and service level to address running challenges. The resource allocation and collaborative scheduling of quayside berth and storage yard are vital issues in the optimization of container terminal handling systems (CTHSs). The allocation of berth in quayside and blocks on storage yard directly affects the running efficiency of CTHS. Consequently, we focus on the berth and yard collaborative allocation for import and export synchronous operations (BYCA-IESOs) and propose the BYCA-IESO research model based on synchronous or asynchronous integrated scheduling strategy by computational logistics. The BYCA-IESO model is a mixed integer quadratic programming model to minimize multiple time consumption of calling liners and the total horizontal transferring distances of yard trailers at container terminals. Furthermore, we design other two allocation policies for comparison on the BYCA-IESO, which are both multistage scheduling strategy profiles. CPLEX 20.1.0 is applied to implement and solve the model and tactics of BYCA-IESO. Accordingly, the feasibility, validity, and relative merits of the models and strategies are obtained and verified by analyzing and comparing multiple numerical experimental results.

\section{Introduction}

The container terminal is a backbone hub node in the international trade logistics network, which is an important distribution center to change the mode of transportation or hand over cargos. The scale and quantity of container terminals both have grown steadily in the influence of economic globalization and with the rapid development of container freight and large-scale container ships. Moreover, the container terminal has definite trends of deep water, operational specialization, and running integration [1-3]. Generally, a container terminal may serve a certain number of vessels simultaneously and the terminal operators need to handle a huge quantity of containers even in a very short period of time. This is undoubtedly conducive to the development of container terminals. When facing a huge development opportunity, challenges to the operation of container terminal handling systems (CTHSs) also become greater than ever. The competition among terminals is fierce and furious. However, as the close links among the economic activities of every country, container terminals play an increasingly important role in the import and export trade of each country. By improving the competition of container terminals, it can promote the economic development and logistics service of the country dramatically where they are located. Hence, it is very necessary and urgent to improve the level of operation and management of CTHS.

Promoting competitiveness of container terminals relies on pushing the continuous improvement of their handling technology and operation efficiency at the tactical and executive levels in significant measure $[4,5]$. It is just about improving resource utilization and task scheduling in the container terminal handling systems (CTHSs). The core production resource at container terminal is always limited and scarce in most situations, such as quayside berths, yard bays, quay cranes, and yard trailers. As the increasing 
number of vessels and containers needs to be served or handled, the CTHS must ensure that all calling liners can moor to be operated and all accompanying containers can be handled in a finite period of time. If the terminal operator cannot allocate the production resource wisely, the departure time of liners has a high probability of delay. Once the delays on some vessels become severe, it not only leads to the congestion for the given terminal but also influences the arrival time of the container ships to the next harbor. Consequently, the container terminal is going to become less competitive gradually since the shipping line is unwilling to choose this terminal. As a result, it is of paramount importance for container terminal operators to arrange resources more availably and rationally and improve the utilization efficiency and response time of key resource pool $[6,7]$.

Generally, the operator of container terminal will develop an operational plan and scheduling schemes over a period of time according to the estimated arrival schedule of liners and the occupation windows of terminal resources. The planning cycle of terminal operators may be hours, days, or weeks. For the CTHS, both berth and yard are the most important tactical and executive resources and lie at the heart of port competition because the working spaces of CTHS are pivotal and depletable $[8,9]$. Hence, a rational, efficient, and robust collaborative allocation of berths and yards can keep CTHS running smoothly and improve terminal operational efficiency dramatically [10].

While developing the running plan by a fixed or flexible cycle, the operator needs to determine where the vessel is planned to moor and where the concomitant containers are expected to be stored. The quayside berth allocation and the yard bay allotment both influence the turnaround time and the hatch hours of calling liners. Besides, they also affect each other because both decide the transferring distance of yard trailers directly. Nevertheless, if only the optimal allocation of quayside berth or one of the storage yards is emphasized separately, the maximum utilization and synergy effect of berth and yard resources cannot be obtained and implemented. It is likely that either berth allocation or yard allotment is optimal. However, the collaborative allocation of berth and yard is not optimal, even not the feasible solution of high quality. Furthermore, the total horizontal transferring distance of yard tailers, which is between quayside and yard, is even less satisfactory. Therefore, it is necessary and significant to consider berth allocation and yard allotment simultaneously.

In this paper, we aim to design and implement the berth and yard collaborative allocation for import and export synchronous operation (BYCA-IESO) optimization by computational logistics. In Section 2, we conduct a literature review of berth allocation problem, yard allotment problem, and computational logistics. The problem description and abstraction of the BYCA-IESO with computational logistics are given in Section 3. We expatiate the formulating process of the BYCA-IESO model in Section 4, and the solutions to BYCA-IESO with different time ticks and allocation strategies are also introduced in this section. In Section 5, the numerical experiments for BYCA-IESO are deigned, executed, contrasted, and evaluated according to the production practice at container terminals by different scheduling time ticks and collaborative allocation strategies within the conceptual framework of computational logistics. Section 6 concludes the paper with some discussions and extensions.

\section{Literature Review and Related Works}

The quayside berth and storage yard are the core resources of CTHS, and the resource utilization, handling capacity, and load balancing of both directly determine the formulation, implementation, and adjustment of container terminal production plan. Accordingly, the berth allocation problem (BAP) and the yard allocation problem (YAP) are two significant scheduling issues in CTHS, which both have the complexity of nonlinearity and uncertainty and are difficult to describe with accurate mathematical models [11-17]. The berth allocation of calling liners affects the yard allotment of import and export containers synchronously, while the resource distribution of storage yard has also a powerful influence on the berth allocation efficiency. The resource allocation of berth and yard influence and constrain each other, and both have strong coupling. Consequently, the service level of CTHS depends on the collaborative allocation and integrated scheduling ability of the above two core resources to a large extent. In order to improve the service level of CTHS, scholars have done a series of research on the BAP, YAP, and the cooperative operation between them.

The BAP has always been the focus and difficulty of scholars' research. In the research of BAP, some scholars have studied the discrete berth scheduling problem. The berth scheduling problem is to reasonably assign the berth of terminal to the given vessels, optimizing the total service time and the utilization of berth [18]. Imai et al. [19] discussed the static berth scheduling problem and established a mathematical model aiming at minimizing the total stay time of ships in port and the dissatisfaction of ship berthing. Hammouti Issam et al. [20] considered the situations that two vessels could moor in a berth at the same time into the model and aimed to optimize the staying cost of vessels at the terminal. Xiang et al. [21] analyzed the factors that influence the execution of operation plan in reality. They proposed a mixed integer programming model to optimize the baseline cost. Xiang and Liu [8] minimized the total cost of deviations between the planned and expected berthing time of the vessel. Agra and Oliveira [22] introduced a model to minimize the service completion time of liners. Barbosa et al. [23] considered the time window constraints in solving discrete berth allocation problem. Sheikholeslami [24] et al. aimed to minimize the vessels' delay time of departure and proposed a model to realize the goal by considering tide effects in terminal with discrete berth.

In fact, in order to make better use of scarce shoreline resources, most berths of container terminals are regarded as being continuously distributed. Yang [25] et al. considered the problem of dynamic arrival of ships under continuous berths and established an integer linear programming model with the goal of minimizing the service time of ships in port. 
Liu [26] et al. aimed to improve the service level by considering some uncertain factors about the arrival and operation time of vessels. Malekahmadi et al. [27] proposed a model to minimize the time of waiting berthing and the total handling time. Thanos [28] et al. aimed to minimize the container transshipment distances between the berth and yard area. Wang [29] et al. intended to optimize the total delay time of completing the operation, cost of quay crane, and carbon emission tax. Abou Kasm [30] et al. introduced a model to optimize the berth and quay crane scheduling, minimizing the total time consumption of waiting to handling. Tan [31] et al. integrated the berth allocation problem and quay crane assignment problem to minimize the time of waiting and delay departure. Al-Refaie and Abedalqader [32] considered continuous berth scheduling problem and proposed two models that mainly aimed to reduce terminal operating costs and improve terminal operation efficiency. Mahpour [33] et al. analyzed several factors affecting terminal operation and obtained the best time to serve vessels. Lin [34] et al. optimized the berth allocation in container terminal by considering the service time and penalty cost.

In reality, quay berths and storage yards, as scarce resources of container terminals, cannot expand indefinitely. With the growth of container throughput, the problems of terminal congestion and low operation efficiency become more and more serious and prominent. In view of the current situations, scholars have considered the scheduling of berths and storage yards synchronously, but the existing results are relatively few. Zhen [35] et al. established a mixed integer model to minimize the ship service cost and yard transportation length by integrating the berth plate and yard plate planning, considering the uncertainty of the location of the ship occupying the berth and the time in port. Le and Zhao [36] dynamically linked berth scheduling and yard container area assignment through the optimal berthing position and established a nonlinear mixed integer model with the goal of minimizing the total activity cost, but it did not consider the time factor. Wang et al. [37] also proposed a mixed integer programming model with the minimum total activity cost for the comprehensive optimization of wharf resources such as discrete berths, yard space, and quay cranes. Li and Jia [38] established a joint optimization model for berth and yard scheduling under uncertain environment by introducing scene variables, which could effectively reduce the wharf congestion rate, but it still did not consider the influence of time factor. Han [39] et al. considered the uncertain factors of ship arrival time and established a mixed integer programming model based on random scenarios. However, in terms of yard scheduling, it only included the constraints related to the total amount of import and export container area. Guo et al. $[40,41]$ meant to optimize the yard trailer travel distance in discrete terminal, but the authors only considered the operation of export container in container terminal. Obviously, the operation of import containers also affects the yard trailer travel distance. Nishimura [42] aimed to minimize the total service time by estimating the handling time in discrete berth. Jian et al. [43] proposed a strategy to solve the berthing congestion problem considering the integrated scheduling in berth and yard system in transshipment container terminal.
Hendriks [44] et al. presented the berth and yard allocation problem at a tactical level and intended to minimize the total container travel distance by solving a mixed integer quadratic program model. Ma [45] et al. considered the berth allocation problem and yard allocation problem simultaneously to minimize the total travel container distance with discrete berth at container terminals. Xu [46] et al. put forward a mixed integer nonlinear programming to minimize the total operating time of CTHS.

Most scholars have considered the berth and yard allocation in transshipment container terminal when researching on the integrated scheduling of the berth and yard. In addition, some researchers have also considered the operation scheduling for import and export containers. Little research on integrating the berth and yard scheduling simultaneously in general container terminal has been done, compared with that in transshipment terminal. However, the existing discussion only considered the operation of export containers. Actually, the import and export containers coexist in operation of container terminals. We cannot simply optimize the handling of export container or import container in making the running plan of berth and yard. In this paper, we expect to integrate the berth and yard scheduling for import and export container in CTHS simultaneously, which is the superposition of nondeterministic polynomial complete problems essentially. The proposal of computational logistics indicates a new approach to the BYCA-IESO with the controllable, customizable, and acceptable computational complexity [47]. The container terminal oriented logistics generalized computation (CTO-LGC) provides the foundation of abstraction and automation for the BYCA-IESO [48]; moreover, the corresponding computing and storage abstract and automated architecture have been initially defined [49]. Consequently, the multiobjective optimization of BYCA-IESO is supposed to be designed and implemented by computational logistics, which is just about to minimize the time of vessels consumed and the transferring distances of yard trailers at the container terminal by optimizing the assignment of quayside berth and the storage yard for import and export containers synchronously.

\section{Problem-Oriented Exploration of Berth and Yard Joint Scheduling by Computational Logistics}

3.1. Problem-Oriented Exploration Using Computational Logistics. In view of the current research situations and ongoing practical requirements, we focus on the BYCAIESO at container terminals by computational logistics. The mixed integer quadratic programming (MIQP) models for BYCA-IESO are proposed to optimize the integrated scheduling of berth and yard simultaneously. The fundamental principles and internal mechanisms are transferred, customized, and targeted purposefully from computer science and engineering to BYCA-IESO within the conceptual framework of computational logistics. As a matter of fact, the classic operation research and the distinct computational 
logistics are integrated to be as a comprehensive solution to scheduling and decision of CTHS whether in theory or in practice. This is exactly one of the unfinished works in our previous research on computational logistics, and it is just about an important piece of the puzzle for computational logistics. The problem-oriented exploration of BYCA-IESO is a sound, positive, and representative annotation and demonstration of the above critical piece.

Now, the BYCA-IESO is abstracted from the visual angle of problem-oriented exploration by the computational logistics. The resource discretization and time tick are the central themes of the abstraction and automation of BYCA-IESO by computational logistics [50]. On the one hand, the resource abstraction of quayside berth is the kernel of BYCA-IESO for the computing mechanization and automation in a broad sense. The traditional BAP can be categorized into two broad categories: discrete berth allocation and continuous berth allocation. We combine both approaches to deal with BAP. With reference to the design ideas and working principles of the computer systems, the quayside berth is resource discretized as fine-grained as possible to make full use of berth resources. The flat length can be 10 meters or 15 meters, or 20 meters at the most, and it is based on the plane layout, equipment configuration, calling liners, and target throughput of the given container terminal. In consideration of the planning cycle periods in CTHS, the decision time tick of BYCA-IESO may be quarter hour, half an hour, or one hour for berth allocation. The above space and time partition matrices are the scheduling cores of the BYCA-IESO.

In a similar manner, the storage yard is divided into four kinds of container sections, which are the import heavy container zones, the import empty container zones, the export heavy container zones, and the export empty container zones, respectively. Every kind of yard zone contains a certain number of blocks, and each block covers some bays, and every bay is a two-dimensional physical matrix for container storage. The storage capacity of every block is constant, which is determined by the civil infrastructure, plane layout, handling technology, and equipment configuration. Consider that every block serves some different purposes that include loading, discharging, collection, distribution, marshalling, and pre-relocation simultaneously. As a result, one block is only assigned to a couple of calling liners at a particular moment. The above is the very discrete space abstraction of storage yard. Meanwhile, the decision time tick of BYCA-IESO is half an hour, one, two or three hours, and four hours at most, for yard allocation according to the actual situations of production practice in CTHS. In other words, the CTO-LGC in quayside berth and storage yard is implemented and executed by the synchronous or asynchronous modes. The quayside berth and storage yard both are the core memory resources at container terminals if the CTHS is considered as the CTO-LGC dedicated system by computational logistics, which two correspond, respectively, to the processor cache and the main memory of CTHS. Thereupon, the above scheduling mode with hybrid time ticks is highly similar to the running of computer systems, especially between processor cache and main memory.
To be more specific, more information about the quayside berth layout and the storage yard configuration of the CTHS is shown in Figure 1. The proposed model is based on the operational analysis of the handling technology and service objects at container terminals. From Figure 1, we can see the logistics service process of the import and export containers for calling liners in terms of quayside berth and storage yard. It mainly consists of three parts, which are shown as follows.

(i) Quay crane loading and discharging containers: after the calling liners moor by the quayside berth, the quay crane (QC) along the quayside is to discharge firstly their import containers needed to be unloaded and then load the export containers that need to be loaded to the given vessel. All arrived vessels must complete this operation within a planning time window according to the shipping schedule.

(ii) Yard trailer horizontal transferring containers: the import containers unloaded from the vessel mooring the berth are going to be horizontally transferred to the assigned blocks of storage yard by the yard trailer (YT). For the export containers needed to be loaded to the vessel, they are also transferred to the assigned berth by the YT. In terms of the whole container terminal, the CTO-LGC for import and export containers is implemented and executed synchronously from an executive level.

(iii) Yard crane stacking, retrieving, receiving, and fetching containers: when the unloaded import containers are transported to the assigned blocks of yard, the yard crane (YC) is to discharge them from the YTs to the blocks of storage yards. The blocks are going to conserve them for a certain time. For the export containers needed to be loaded to the vessels, they are usually stacked in the assigned blocks of yards for a period of time before the vessels arrive at the terminal. When the liners arrive at the terminal, the export containers are going to be retrieved and loaded from the block to the YTs by the YC. In addition, the YC fulfills the functions of receiving and fetching containers during the collection and distribution of CTHS.

By reasons of the foregoing, the QC, YT, and YC all can be abstracted as the parallel, heterogeneous, and reconfigurable CTO-LGC processor farms by computational logistics. Consequently, the quayside berth and the storage yard construct the heterogeneous, three-dimensional, discrete, and unit collaborative storage architecture, which is similar to the synergy between processor cache and main memory in computer systems. Accordingly, both form the operational center of CTHS. Naturally, the problem-oriented exploration of BYCAIESO become an important issue of planning and scheduling of CTHS, especially at the tactical and executive levels.

\subsection{Berth and Yard Collaborative Allocation Problem} Description. No matter in theory or in practice, the shipping company can provide the estimated time of arrival, estimated time of departure, and the number of containers to be 


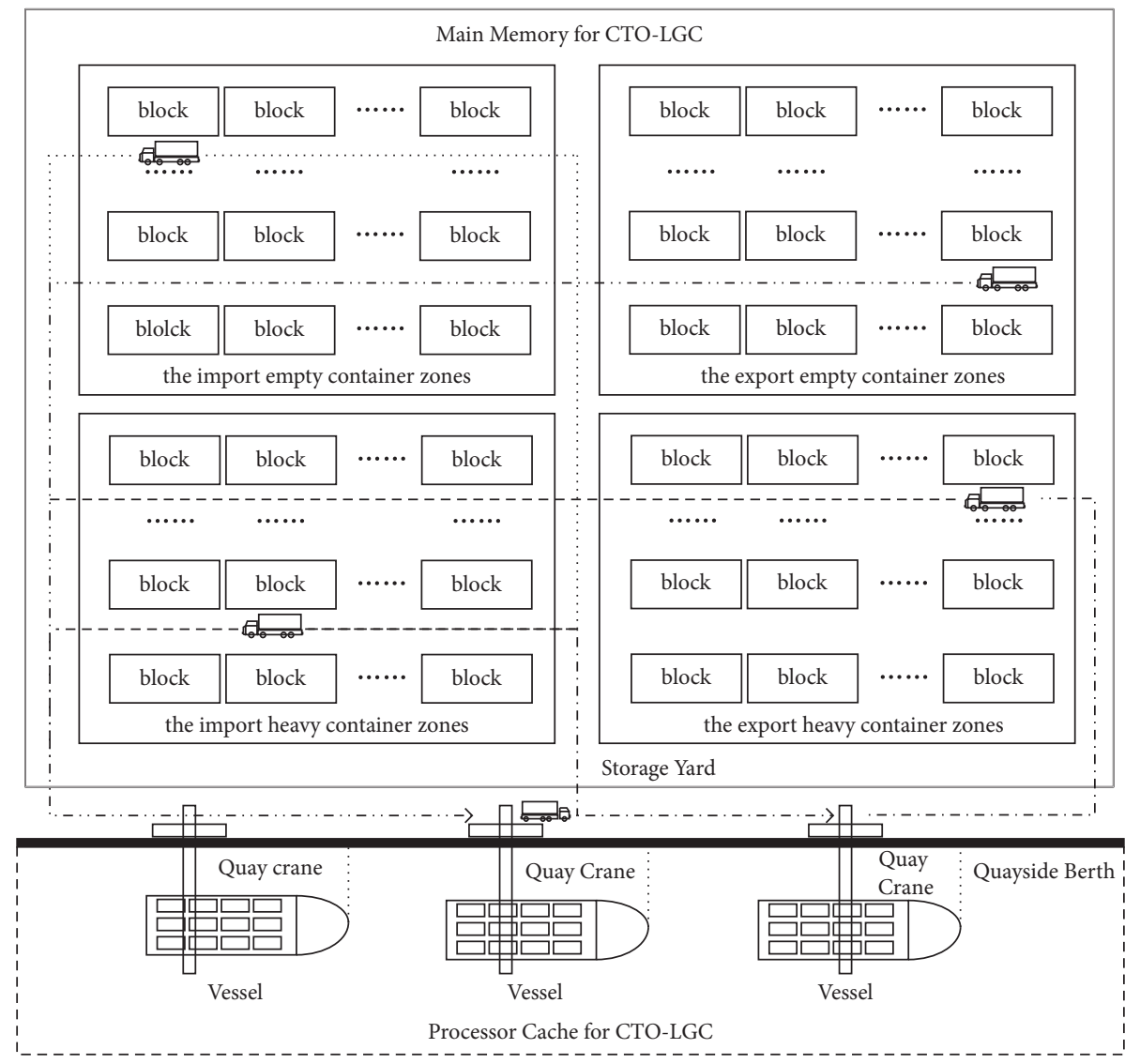

FIGURE 1: Abstract collaborative storage architecture for CTHS by computational logistics.

loaded and unloaded for the liners. The terminal operator can make the berth allocation plan according to the above obtained information, and the container terminal operator is to formulate a loading and discharging plan of the import and export containers for the calling liners. When the planners assign the berth along quayside and the blocks on yard for the given calling liner, they must take its arrival time, departure time, and handling container volume into account.

Actually, the container ship is dynamically arriving at the terminal, instead of just following the schedule. Thus, the terminal operator can only formulate the loading and unloading plan according to a certain planning time window. At the same time, the working plan is rolling update dynamically. The planning time window consists of several time segments. The length of time segment is just the above time tick of BYCA-IESO, which is the running frequency of CTHS and may be different for the berth allocation and the yard allotment separately.

The container ship arrived at the port within a planning window is going to occupy the quayside berth and storage yard resources in a certain period of time dynamically. It should be emphasized that the holding time of berth and yard is distinctly different for a container ship, and the latter is far longer than the former because of the depositing time of export containers and the retention time of import containers.

However, the working space resources of quayside berth and storage yard in CTHS are very limited and scarce, so the terminal operator must ensure to reduce the occupation of berth and yard by vessels as far as possible under the conditions of meeting the running requirements of vessels to improve the operational efficiency of the port. When the vessels within the planning window arrive at the terminal one after another, they are to moor at the assigned berth according to the production plan formulated by the terminal operator to launch the operation of unloading import containers and loading export containers. The YT implements the horizontal transferring of the import containers unloaded from vessels to the designated blocks, and the YT also executes the horizontal transferring of the export containers in the designated spot that need be loaded to the vessels to the assigned quayside berth.

At the same time, the distribution of the quayside berth and the storage yard determine the total horizontal transferring distances of YTs, which affect the loading and unloading efficiency of the vessel in significant measure. Therefore, it is extremely necessary to integrate scheduling of the berth and yard by considering the situations of the berth allocation, the yard allocation, and the total horizontal transferring distances of YTs, so as to improve the CTO-LGC running efficiency of CTHS. Consequently, the occupancy resources of quayside berth and storage yard by vessels can be represented from the dimensions of time and space under the multiple constraints. It is a typical multispace cooperative allocation problem by computational logistics. There are already available, mature, efficient, and robust solutions 
to this problem, which is just the classical and productive collaboration between processor cache and main memory in computer systems. The problem description of BYCA-IESO proceeds as follows.

In terms of multiple time dimensional constraints, for the $\mathrm{BAP}$, there are three major parts of time to be considered in the BYCA-IESO as follows. (1) The first is the time of waiting for berth on the vessels after it arrives at the port to prepare for loading and discharging operations. (2) The second is the handling time of the moored vessels. (3) The last is the hold-up time that moored vessels occupy the berth. For the YAP, it is mainly to meet the requirements of container temporary storage. For import containers, they still need to be retained for a period of time after being unloaded and transported to the storage yard for storage. Therefore, for the import containers, the resource occupying duration of import storage yard is from its time of beginning unload operation to its ending storage time in yard. For export containers, the port usually performs the pre-storage operation, which is delivering all containers that need to be loaded onto the arrived vessel to the storage yard before the vessel arrives at the port. Therefore, the period time of the export containers occupying the blocks of the export storage yard is from the start time of the pre-storage operation to the end time of the loading for the specific liner.

In terms of multiple space dimensional constraints, terminal operators assign quayside berths according to the length of vessels and determine the range of container blocks that can be allocated to vessels according to the quantity of import and export containers that need to be loaded and discharged. The berth allocation of vessels affects their choice of blocks that need to be occupied in the yard. At the same time, the option of the occupied blocks on storage yard also exerts significant influences over berth allocation. As a CTO-LGC horizontal transferring processor, the YT connects the wharf apron production subsystem and the storage yard service subsystem. Therefore, in order to jointly dispatch the berth and yard and improve the CTO-LGC efficiency of the terminal, the travel path of the YT must be optimized, rather than only considering from the single dimension of time constraints. In addition, in terms of berths allocation and yard allotment, there are certain constraints in space constraints. For example, the berth can only be occupied by one vessel at most at one point, and no more than two vessels can be allowed to carry out the stacking operation at the same time in the same block.

The above abstraction of BYCA-IESO is remarkably similar to the storage architecture in computer systems. Nevertheless, the running of BYCA-IESO is much more complicated than the situations of computer systems because the constraint conditions of the BYCA-IESO are more complex and harsher than the corresponding part of computer systems. The changes in constraint conditions are mainly because the target objects of CTO-LGC, which is just about manifold liners and containers, have numerous physical properties that include physical dimensions, handling specifications, logistics execution, collection and distribution modes, and so on.

In this paper, we aim to optimize the total consumption time of vessels at the terminal and the total transferring distances of the YT during a planning window. For the terminal operator, the most intuitive way to improve the operation efficiency of the CTHS is to optimize the time consumption of arriving ships and the travel path of the YTs. For the shipping company, the less the time spent by vessels at the target port, the smaller the cost of cargo transportation and the higher the efficiency of cargo transportation are. Therefore, it is reasonable to take the total consumption time of vessels at the given terminal and the total transferring distances of the YT set as the optimization objectives of BYCA-IESO.

\section{Model Formulation of Berth and Yard Collaborative Allocation with Computational Logistics}

We have described the main service processes of the berth and yard in the Section 3 and are aiming at the multiobjective optimization of BYCA-IESO. To achieve the optimization goal, we construct and design the MIQP models by the two different integrated scheduling strategies. One of the integrated scheduling strategies considers a simple situation that the time ticks for the quayside berth service system and storage yard production system are synchronous. We call this strategy berth and yard integrated scheduling with synchronous decision time ticks (BYISSDTT). The other scheduling strategy is more flexible and more complicated than BYIS-SDTT. In the actual operations in CTHS, the time ticks for the berth service subsystem and yard operating subsystem are asynchronous while assigning the berth and yard at container terminals. We call it berth and yard integrated scheduling with asynchronous decision time ticks (BYIS-ADTT). Actually, the BYIS-SDTT is the basic scheduling strategy compared to the BYIS-ADTT, and the BYIS-SDTT is a particular case of the BYIS-ADTT. We also propose two other different scheduling strategies for comparison based on the following MIQP models. Thus, there are mainly four kinds of berth and yard collaborative allocation scheduling strategies in this paper. The first two kinds are the main models based on integrated scheduling strategy that are BYIS-SDTT and BYIS-ADTT. The latter two scheduling strategies are for comparisons with the first two strategies based on staged scheduling strategy. In this section, we are going to define the formulation of the BYCAIESO model and all the four collaborative allocation strategies for berth and yard.

\subsection{Description of Symbols and Variables}

\subsubsection{Input Variables}

$\mathrm{V}$ : set of all vessels $i$.

$\mathrm{J}$ : set of berth segment $\mathrm{k}$.

T: set of all time periods $t$ that allow vessels to loading and unloading operation.

T1: set of all time periods $t 1$ that allow vessels to perform pre-storage operation. 
T2:set of all time periods $t 2$ that allow unloaded containers to retain in the storage yard.

S1: set of all blocks hl of the import heavy container storage yard.

S2: set of all blocks el of the import empty container storage yard.

Q1: set of all blocks hq of the export heavy container storage yard.

Q2: set of all blocks eq of the export empty container storage yard.

$\left[\alpha_{i}^{1}, \beta_{i}^{1}\right]$ : the range of blocks that vessel $i$ can occupy in import heavy container yard.

$\left[\alpha_{i}^{2}, \beta_{i}^{2}\right]$ : the range of blocks that vessel $i$ can occupy in import empty container yard.

$\left[\xi_{i}^{1}, \eta_{i}^{1}\right]$ : the range of blocks that vessel $i$ can occupy in export heavy container yard.

$\left[\xi_{i}^{2}, \eta_{i}^{2}\right]$ : the range of blocks that vessel $i$ can occupy in export empty container yard.

$L_{i}$ : the length of vessel $i$.

$A_{i}$ : the arrival time of vessel $i$.

$H_{i}$ : the loading and unloading operation time of vessel $i$.

$\mathrm{Pt}_{i}$ : the pre-storage operation time of vessel $i$.

$\mathrm{Et}_{i}$ : the retain time of vessel $i$.

$\mathrm{D}_{\mathrm{ihl}}$ : the distance from the berth segment that vessel $i$ occupied to the block hl.

$\mathrm{D}_{\text {iel }}$ : the distance from the berth segment that vessel $i$ occupied to the block el.

$\mathrm{D}_{\text {ihq }}$ : the distance from the berth segment that vessel $i$ occupied to the block hq.

$D_{\text {ieq }}$ : the distance from the berth segment that vessel $i$ occupied to the block eq.

M: a sufficiently large real number.

$\omega_{1}$ : the weight coefficient of the total consumption time of the given calling liner set in the objective function.

$\omega_{2}$ : the weight coefficient of the total horizontal distances of the given yard trail set in the objective function.

\subsubsection{Decision Variables}

$b_{i}$ : the upper bound of berth segment that vessel $i$ occupied.

$H s_{i}$ : the start time of the pre-storage operation for vessel $i$.

$g_{i}$ : the time that vessel $i$ starts mooring by the assigned berth.

$s_{i}$ : the start loading and unloading operation time of vessel i.

$e_{i}$ : the end loading and unloading operation time of vessel i.

$d_{i}$ : the departure time of vessel $\mathrm{i}$.

$H r_{i}$ : the time that the import containers of vessel $i$ leave the import container yard.
$C_{i j}$ : binary variables, 1 if vessel $i$ is on the left side of vessel $j$, and 0 otherwise.

$A_{i j}$ : binary variables, 1 if vessel $i$ arrives earlier than vessel $j$, and 0 otherwise.

$N_{i k}$ : binary variables, 1 if vessel $i$ is moored in berth segment $k$, and 0 otherwise.

$X_{i t_{1}}^{1}$ : binary variables, 1 if the import container of vessel $i$ is in the import container storage yard area at time $t$, and 0 otherwise.

$X_{i t_{2}}^{2}$ : binary variables, 1 if the export container of vessel $i$ is in the export container storage yard at time $t$, and 0 otherwise.

$\sigma_{i h l}^{1}$ : binary variables, 1 if vessel $i$ occupies the block hl of the import heavy container storage yard, and 0 otherwise.

$\sigma_{i e l}^{2}$ : binary variables, 1 if vessel $i$ occupies the block el of the import empty container storage yard, and 0 otherwise.

$\varphi_{\text {ihq }}^{1}$ : binary variables, 1 if vessel $i$ occupies the block hq of the export heavy container storage yard, and 0 otherwise.

$\varphi_{\text {ieq }}^{2}$ : binary variables, 1 if vessel $i$ occupies the block eq of the export empty container storage yard, and 0 otherwise.

$\mu_{i t_{1}, h l}^{1}$ : binary variables, 1 if vessel $i$ occupies the block hl of the import heavy container storage yard at time $t$, and 0 otherwise.

$\mu_{i t, e l}^{2}$ : binary variables, 1 if vessel $i$ occupies the block el of the import empty container storage yard at time $t$, and 0 otherwise.

$v_{i t_{2} h q}^{1}:$ binary variables, 1 if vessel $i$ occupies the block hq of the export heavy container storage yard at time $t$, and 0 otherwise.

$v_{i t_{2} e q}^{2}$ : binary variables, 1 if vessel $i$ occupies the block eq of the export empty container storage yard at time $t$, and 0 otherwise.

4.2. Model Formulation of Berth and Yard Integrated Scheduling with Synchronous Decision Time Tick. The objective function of the MIQP model for the integrated scheduling of berth and yard resources is to optimize the berth and yard scheduling scheme of expected arriving ships within a flexible and tunable planning cycle from multiple operational constraints originating from the dimensions of time and space. For the time dimension, this paper mainly optimizes the total consumption time at the terminal. For the spatial dimension, this paper mainly aims to optimize the total horizontal transferring distances of the YT.

The total consumption time in CTHS in a planning cycle mainly includes three indicators, which are the waiting time of liners for mooring, the berthing time of vessels at the terminal, and the handling time of liners. The waiting time of liners for mooring means the waiting time of all vessels before they moor to the berth after arriving at the port in a 
given planning cycle. The berthing time of vessels at the terminal refers to the total time of all vessels occupying berths in the planning cycle. The handling time is the time consumption for the execution of loading and discharging operation of all vessels in the planning cycle.

The waiting time of vessel $i$ for mooring can be calculated by the following formula:

$$
F_{1}(i)=g_{i}-A_{i}
$$

The berthing time of vessel $i$ at the port can be calculated by the following formula:

$$
F_{2}(i)=d_{i}-g_{i}
$$

The loading and unloading time of vessel $i$ can be calculated by the following formula:

$$
F_{3}(i)=e_{i}-s_{i} .
$$

Therefore, the total time consumption of vessel $i$ at the port in a planning period can be obtained by the following formula:

$$
F(i)=f_{1}(i)+f_{2}(i)+f_{3}(i)
$$

The total horizontal transferring distances of the YT refers to the distances from the mooring location of vessel $i$ to the blocks it occupies on the storage yard, which can be calculated by the following formula:

$$
R(i)=N_{i k} \cdot\left(\sigma_{i h l}^{1} \cdot D_{i h l}^{1}+\sigma_{i e l}^{2} \cdot D_{i e l}^{2}+\varphi_{i h q}^{1} \cdot D_{i h q}^{1}+\varphi_{i e q}^{2} \cdot D_{i e q}^{2}\right) .
$$

Since the objective function involves the dimension of time and space and has different dimensions and dimensional units, in order to eliminate the dimensional influences between the two indicators, the data related to the two indicators need to be normalized to eliminate the unit limitation between the two indicators. As for the selection of normalization processing treatment, we adopt the max-min standardization method to carry out the normalization processing of objective function indicators. The formula of this method is as follows:

$$
X^{\prime}=\frac{X-\min (X)}{\max (X)-\min (X)} .
$$

The total time consumption at terminals and the total travel distances of the YT, which both constitute the objective function of BYCA-IESO, are not constant and are going to change with different scheduling schemes. Therefore, we adopt the empirical constants $m$ and $n$ to represent the maximum and minimum values among them. Therefore, the normalization of the total consumption time at port and the total travel distance of the truck can be processed by the following formula:

$$
\begin{aligned}
F^{\prime}(i) & =\frac{f(i)-n}{m-n}, \\
R^{\prime}(i) & =\frac{r(i)-n}{m-n} .
\end{aligned}
$$

Consequently, the proposed MIQP model of BYCAIESO is formulated as follows:

$$
\operatorname{Min} Z=\sum_{i \in V} \omega_{1} \cdot F^{\prime}(i)+\sum_{i \in V} \omega_{2} \cdot R^{\prime}(i)
$$

s.t.

$$
\begin{gathered}
H s_{i}=g_{i}-A_{i}, \forall i \in V, \\
H r_{i}=e_{i}+E t_{i}, \forall i \in V, \\
g_{i} \geq A_{i}, \forall i \in V, \\
s_{i}-g_{i} \geq 1, \forall i \in V, \\
e_{i}-s_{i} \geq H_{i}, \forall i \in V, \\
D_{i}-e_{i} \geq 1, \forall i \in V,
\end{gathered}
$$

$$
H s_{i} \leq t_{1} \cdot X_{i t_{1}}^{1}+M \cdot\left(1-X_{i t_{1}}^{1}\right), \forall i \in V, \forall t_{1} \in T_{1} \text {, }
$$

$$
\begin{gathered}
E_{i} \geq t_{1} \cdot X_{i t_{1}}^{1}, \forall i \in V, \forall t_{1} \in T_{1}, \\
\sum_{t_{1} \in T_{1}} X_{i t_{1}}^{1}=e_{i}-H s_{i}+1, \forall i \in V, \\
H r_{i} \geq t_{2} \cdot X_{i t_{2}}^{2}, \forall i \in V, \forall t_{2} \in T_{2}, \\
s_{i} \leq t_{2} \cdot X_{i t_{2}}^{2}+M \cdot\left(1-X_{i t_{2}}^{2}\right), \forall i \in V, \forall t_{2} \in T_{2}, \\
\sum_{t_{2} \in T_{2}} X_{i t_{2}}^{2}=H r_{i}-s_{i}+1, \forall i \in V, \\
b_{i}-L_{i} \geq 0, \forall i \in V, \\
d_{i} \leq g_{j}+M \cdot\left(1-A_{i j}\right), \forall i, j \in V, i \neq j, \\
b_{i} \leq b_{j}-L_{j}+M \cdot\left(1-C_{i j}\right), \forall i, j \in V, i \neq j, \\
A_{i j}+A_{j i}+C_{i j}+C_{j i} \geq 1, \forall i, j \in V, i \neq j, \\
\alpha_{i}^{2} \leq \sum_{l \in S^{2}} \sigma_{i l}^{2} \leq \beta_{i}^{2}, \forall i \in V, \\
b_{i} \geq k \cdot N_{i k}, \forall i \in V, \forall k \in J, \\
b_{i} \leq k \cdot N_{i k}+M \cdot\left(1-N_{i k}\right), \forall i \in V, \forall k \in J, \\
\sum_{i k} \sigma_{i l}^{1} \leq \beta_{i}^{1}, \forall i \in V,
\end{gathered}
$$




$$
\begin{aligned}
& \xi_{i}^{1} \leq \sum_{q \in Q^{1}} \varphi_{i q}^{1} \leq \eta_{i}^{1}, \forall i \in V \\
& \xi_{i}^{2} \leq \sum_{q \in Q^{2}} \varphi_{i q}^{2} \leq \eta_{i}^{2}, \forall i \in V, \\
& \mu_{i t_{1} l}^{1} \leq \frac{\sigma_{i l}^{1}+X_{i t_{1}}^{1}}{2}, \forall i \in V, \forall t_{1} \in T_{1} \text {, } \\
& \mu_{i t_{1} l}^{1} \geq \frac{\sigma_{i l}^{1}+X_{i t_{1}}^{1}-1}{2}, \forall i \in V, \forall t_{1} \in T_{1} \text {, } \\
& \mu_{i t_{1} l}^{2} \leq \frac{\sigma_{i l}^{2}+X_{i t_{1}}^{1}}{2}, \forall i \in V, \forall t_{1} \in T_{1} \text {, } \\
& \mu_{i t_{1} l}^{2} \geq \frac{\sigma_{i l}^{2}+X_{i t_{1}}^{1}-1}{2}, \forall i \in V, \forall t_{1} \in T_{1} \text {, } \\
& v_{i t_{2} q}^{1} \leq \frac{\varphi_{i q}^{1}+X_{i t_{2}}^{2}}{2}, \forall i \in V, \forall t_{2} \in T_{2} \text {, } \\
& v_{i t_{2} q}^{1} \geq \frac{\varphi_{i q}^{1}+X_{i t_{2}}^{2}-1}{2}, \forall i \in V, \forall t_{2} \in T_{2} \text {, } \\
& v_{i t_{2} q}^{2} \leq \frac{\varphi_{i q}^{2}+X_{i t_{2}}^{2}}{2}, \forall i \in V, \forall t_{2} \in T_{2}, \\
& v_{i t_{2} q}^{2} \geq \frac{\varphi_{i q}^{2}+X_{i t_{2}}^{2}-1}{2}, \forall i \in V, \forall t_{2} \in T_{2} \text {, } \\
& \sum_{l \in S^{1}} \mu_{i t_{1} l}^{1} \leq 2, \forall i \in V, \forall t_{1} \in T_{1}, \\
& \sum_{l \in S^{2}} \mu_{i t_{1} l}^{2} \leq 2, \forall i \in V, \forall t_{1} \in T_{1}, \\
& \sum_{q \in Q^{1}} v_{i t_{2} q}^{1} \leq 2, \forall i \in V, \forall t_{2} \in T_{2}, \\
& \sum_{q \in Q^{2}} v_{i t_{2} q}^{2} \leq 2, \forall i \in V, \forall t_{2} \in T_{2} .
\end{aligned}
$$

Objective function (8) aims to minimize the weighted sum of the total time consumption at port and the total horizontal transferring distances of the YT for the all expected arriving vessels within a planning cycle. The summation of the two weight coefficients $\omega_{1}$ and $\omega_{2}$ is 1 . Constraint (9) calculates the variable $H s_{i}$, and it means the start time of the pre-storage operation for vessel I that is equal to its arrival time $A_{i}$ minus its export containers' prestorage operation time $\mathrm{Pt}_{i}$. Constraint (10) calculates the variable $\mathrm{Hr}_{i}$, and it means the end retention time of vessel $i$ for its import containers that equals its end operating time $e_{i}$ plus its import container retention time $\mathrm{Et}_{i}$. Constraint (11) ensures that the vessel berthing completion time $g_{i}$ is not earlier than its arrival time $A_{i}$. Constraint (12) intends that the vessel launching loading and discharging operation time $s_{i}$ is not earlier than its mooring completion time $g_{i}$. Constraint (13) implies that the interval between the vessel starting handling operation time $s_{i}$ and its ending handling operation time $e_{i}$ is greater than its operation time $H_{i}$. Constraint (14) ensures that the vessel departure time $d_{i}$ is not earlier than its completion time $e_{i}$. Constraints (15) and (16) determine the time period when the import containers are in the import container storage yard by variable $X_{i t_{1}}^{1}$. Constraint (17) guarantees that the variable $X_{i t_{1}}^{1}$ always equals 1 when the import container is in the import container storage yard at time $t_{1}$. Constraints (18) and (19) determine the time period when the export containers are in the export container storage yard by variable $X_{i t_{2}}^{2}$. Constraint (20) guarantees that the variable $X_{i t_{2}}^{2}$ always equals 1 when the import container is in the import container storage yard at time $t_{2}$. Constraint (21) ensures that the lower bound berth segment occupied by vessel $i$ does not exceed the berth boundary. Constraints (23)-(25) guarantee that the berth occupied by the arrived vessel at the port has no conflict in the two dimensions of time and space. Constraints (25) and (26) determine the upper berth segment $k$ the vessel $i$ occupies by variable $\mathrm{N}_{\mathrm{ik}}$. Constraint (27) ensures that the vessel $i$ can only moor at a certain berth segment. Constraint (28) guarantees that the total blocks occupied by each vessel in the import heavy container storage yard do not exceed the upper and lower limits it can occupy. Constraint (29) ensures that the total blocks occupied by each vessel in the import empty container storage yard do not exceed the upper and lower limits it can occupy. Constraint (30) ensures that the total blocks occupied by the given vessel in the export heavy container storage yard do not exceed the upper and lower limits it can occupy. Constraint (31) ensures that the total blocks occupied by each vessel in the export empty container storage yard do not exceed the upper and lower limits it can take up. Constraints (32) and (33) imply that $\mu_{i t_{1} h l}^{1}=1$, if $\sigma_{i h l}^{1}=1$ and $X_{i t_{1}}^{1}=1$. It indicates whether each vessel occupies the export heavy container block hl at time $t_{1}$. Constraints (34) and (35) imply that $\mu_{i t_{1} e l}^{2}=1$, if $\sigma_{i e l}^{2}=1$ and $X_{i t_{1}}^{1}=1$. It indicates whether each vessel occupies the export empty container block el at time $t_{1}$. Constraints (36) and (37) imply that $v_{i t_{2} h q}^{1}=1$, if $v_{i t_{2} h q}^{1}=1$ and $X_{i t_{2}}^{2}=1$. It indicates whether each vessel occupies the import heavy container block hq at time $t_{2}$. Constraints (38) and (39) imply that $v_{i t_{2} e q}^{1}=1$, if $v_{i t_{2} e q}^{1}=1$ and $X_{i t_{2}}^{2}=1$. It indicates whether each vessel occupies the import empty container block eq at time t2. Constraint (40) ensures that the block hl in the import heavy container storage yard can occupy no more than two vessels simultaneously. Constraint (41) ensures that the block el in the import empty container storage yard can occupy no more than two vessels simultaneously. Constraint (42) ensures that the block hq in the export heavy container storage yard can occupy no more than two vessels simultaneously. Constraint (43) assures that the block eq in the export empty container storage yard can occupy no more than two vessels concurrently. The above is the MIQP for BYCA-IESO with the BYIS-SDTT, which makes good use of 
computational logistics to describe the operation of BYCAIESO.

4.3. Model Formulation of Berth and Yard Integrated Scheduling with Asynchronous Decision Time Tick. In the proposed model in Section 4.2, we mainly consider that the blocks on the storage yard cannot be occupied by more than three vessels at the same moment. The time tick for the berth allocation and yard allotment is the same. However, the updating speed of block occupation on the storage yard is slower than that of quayside berth in practice. Meanwhile, the container of each vessel stored in the yard areas takes much more time than its berthing time in the terminal. The container inventory in these four different container zones does not change in real time. Only when there are vessels to operate in the terminal, the inventory of yard areas will change. While the terminal operators allocate the berth and yard resources, they make allocation plans based on the different time ticks. That is, the hold-up time when the container is stored in the yard and the time when the ship is moored are not completely synchronized. Therefore, the scheduling time tick of the storage yard is not synchronized with that of the berth system.

We build another model with wider applicability based on the model proposed in Section 4.2. Most of the variables are the same between them. To formulate this new model, we firstly need to define several new variables, which are shown as follows:

$T_{3}$ : set of all time periods $t_{3}$ that allow vessels to perform pre-storage operation.

$T_{4}$ : set of all time periods $t_{4}$ that allow unloaded containers to retain in the storage yard.

$k$ : the time step length in yard is $k$ times that in berth. $Y_{i t_{3}}$ : binary variables, 1 if the import container of vessel $i$ is in the import container storage yard area at time $t$, and 0 otherwise.

$Y_{i t_{4}}$ : binary variables, 1 if the export container of vessel $i$ is in the export container storage yard at time $t$, and 0 otherwise.

The new model is formulated as follows:

$$
\operatorname{Min} Z=\sum_{i \in V} \omega_{1} \cdot F^{\prime}(i)+\sum_{i \in V} \omega_{2} \cdot R^{\prime}(i)
$$

s.t. constraints (9)-(32), and (41)-(44):

$$
\begin{gathered}
Y_{i t_{3}} \geq X_{i j}^{1}, \\
Y_{i t_{3}} \leq \sum_{j=k \cdot t_{3}} X_{i j}^{1}, \\
Y_{i t_{4}} \geq X_{i j}^{2}, \\
Y_{i t_{4}} \leq \sum_{j=k \cdot t_{4}} X_{i j}^{2},
\end{gathered}
$$

$$
\begin{aligned}
& \mu_{i t_{1} l}^{1} \leq \frac{\sigma_{i l}^{1}+Y_{i t_{3}}}{2}, \forall i \in V, \forall t_{1} \in T_{1} \\
& \mu_{i t_{1} l}^{1} \geq \frac{\sigma_{i l}^{1}+Y_{i t_{3}}-1}{2}, \forall i \in V, \forall t_{1} \in T_{1} \text {, } \\
& \mu_{i t_{1} l}^{2} \leq \frac{\sigma_{i l}^{2}+Y_{i t_{3}}}{2}, \forall i \in V, \forall t_{1} \in T_{1} \text {, } \\
& \mu_{i t_{1} l}^{2} \geq \frac{\sigma_{i l}^{2}+Y_{i t_{3}}-1}{2}, \forall i \in V, \forall t_{1} \in T_{1} \text {, } \\
& v_{i t_{2} q}^{1} \leq \frac{\varphi_{i q}^{1}+Y_{i t_{4}}}{2}, \forall i \in V, \forall t_{2} \in T_{2} \text {, } \\
& v_{i t_{2} q}^{1} \geq \frac{\varphi_{i q}^{1}+Y_{i t_{4}}-1}{2}, \forall i \in V, \forall t_{2} \in T_{2} \text {, } \\
& v_{i t_{2} q}^{2} \leq \frac{\varphi_{i q}^{2}+Y_{i t_{4}}}{2}, \forall i \in V, \forall t_{2} \in T_{2} \text {, } \\
& v_{i t_{2} q}^{2} \geq \frac{\varphi_{i q}^{2}+Y_{i t_{4}}-1}{2}, \forall i \in V, \forall t_{2} \in T_{2} \\
& X_{i j}^{1} \in\{0,1\}, j=k \cdot t_{3}, k \cdot t_{3}-1, \cdots, k \cdot t_{3}-(k-1), \\
& X_{i j}^{2} \in\{0,1\}, j=k \cdot t_{4}, k \cdot t_{4}-1, \cdots, k \cdot t_{4}-(k-1) .
\end{aligned}
$$

Constraints (46)-(49) are to convert the scheduling time tick of the quayside berth to the time tick of the storage yard. Constraints (50) and (51) imply that $\mu_{i t_{3} h l}^{1}=1$, if $\sigma_{i h l}^{1}=1$ and $Y_{i t_{3}}=1$. It indicates whether each vessel occupies the export heavy container block hl at time $t_{3}$. Constraints (52) and (53) imply that $\mu_{i t_{3} e l}^{2}=1$, if $\sigma_{i e l}^{2}=1$ and $X_{i t_{2}}^{2}=1$. It indicates whether each vessel occupies the export empty container block el at time $t_{1}$. Constraints (54) and (55) imply that $v_{i t_{4} h q}^{1}=1$, if $v_{i t_{4} h q}^{1}=1$ and $Y_{i t_{4}}=1$. It indicates whether each vessel occupies the import heavy container block hq at time $t_{4}$. Constraints (56) and (57) imply that $v_{i t_{4} e q}^{1}=1$, if $v_{i t_{4} e q}^{1}=1$ and $Y_{i t_{4}}=1$. It indicates whether each vessel occupies the import empty container block eq at time $t_{4}$.

Figure 2 shows the procedure of the MIQP model for BYCA-IESO with the BYIS-ADTT to determine the berth and yard allocation scheme. Essentially, the MIQP model with the BYIS-ADTT covers that with the BYIS-SDTT. The difference between both is whether there is the component to determine if the scheduling time ticks for the quayside berth and the storage yard are identical or not. The MIQP model for BYCA-IESO with BYIS-SDTT is a special situation of that with BYIS-ADTT, and the scheduling time tick of the former for berth and yard allocation is the same. There are four main steps to determine the optimal berth and yard allocation scheme in the MIQP model for BYCA-IESO by BYIS-ADTT. The details of these steps are shown as follows. 


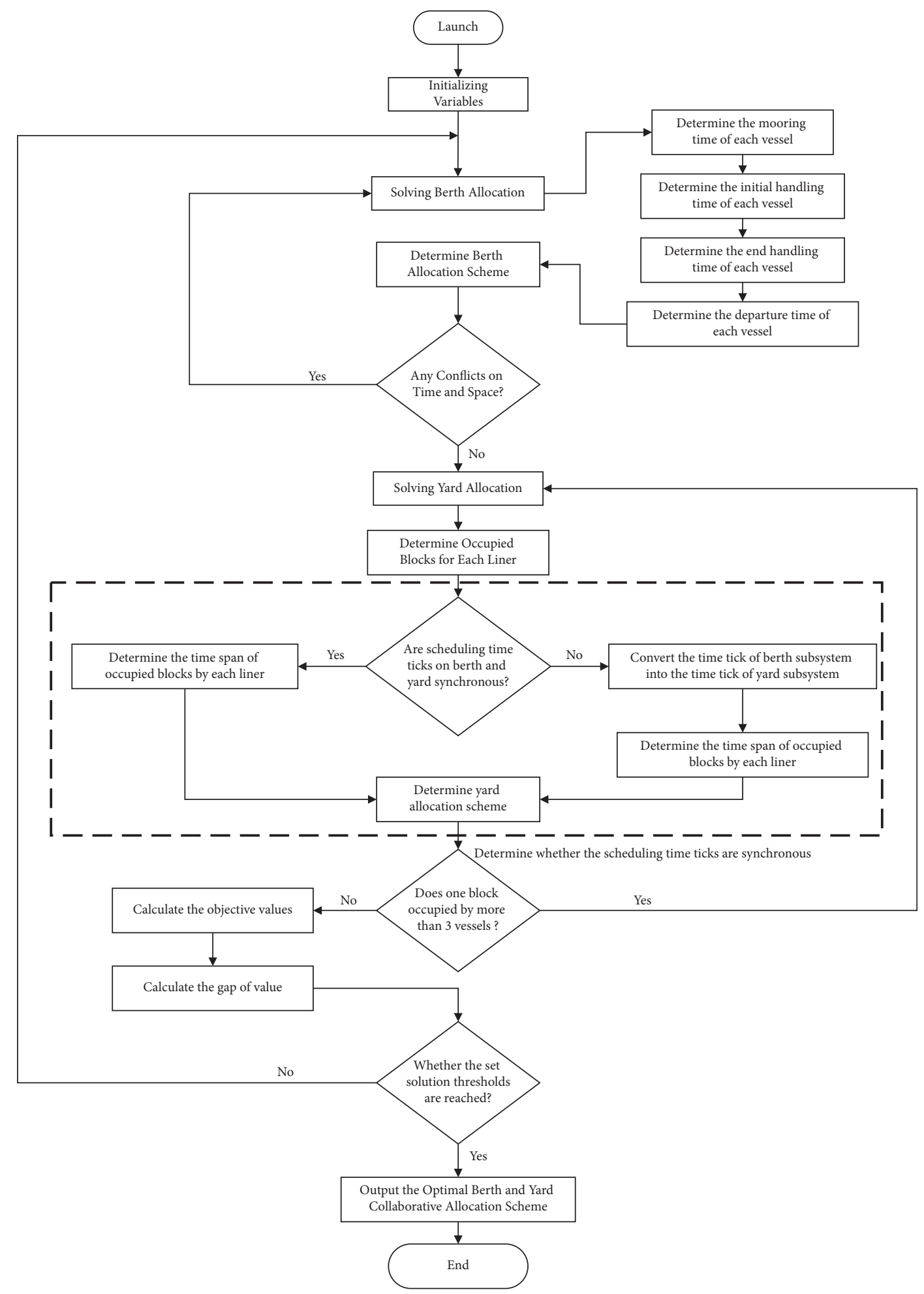

FIGURE 2: The solving process of integrated scheduling strategies for BYIS-SDTT and BYIS-ADTT.

Step one: startup and initializing the values of input variables of the BYCA-IESO model.

Step two: allocating the berth to each vessel expected to arrive. In this step, the mooring berth time, the start handling time, the end handling time, and the departure time for each liner all are determined explicitly. The berth segments that are occupied by each vessel are also confirmed. After working out the berth allocation plan for the liners, the related time to each service procedures for liners is acquired one by one. Subsequently, we need to determine whether there are some conflicts on the constraints of time and space. If there are any conflicts, restart the berth allocation scheduler. Otherwise, the procedure goes to the next step. 
Step three: allocating the yard blocks to each calling liners. The yard allocation is based on the berth allocation in step two. Above all, we allocate the four types of blocks to each vessel separately. Then, we need to determine the time spans for each type of containers occupying the blocks. After defining those, we judge whether the scheduling time ticks for berth service and yard production are same. If the two are identical, we directly determine the time span of occupying blocks based on the time tick related to the given vessel mooring by berth. If not, we need to convert the time tick for berthing into the time tick of storage yard running. After that, we can determine the occupying time of each vessel for the corresponding blocks. If each block in four types of yard zones is occupied by no more than three vessels, the procedure goes to the next step. If not, restart the yard allocation scheduler.

Step four: compare and determine the optimal allocation scheme. In this step, the berth allocation and the yard allotment are determined simultaneously. We calculate the objective values and the corresponding gap. If the gap of objective value is lower than the default setting or the solving time reaches the total solving time limitation, the procedure stops solving and outputs the optimal schemes. If not, the procedure goes to step two.

4.4. Berth and Yard Collaborative Allocation Scheduling Strategy. As previously mentioned, we propose a MIQP model based on the integrated scheduling of berth and yard resources for the operations of import and export containers simultaneously, which are just about BYIS-SDTT and BYISADTT. To verify the superiority and validity of the model and tactics, we will introduce other scheduling strategies to compare with them.

The scheduling strategies to compare are the staged scheduling tactics, which are to consider berth allocation and yard allotment separately. In this section, we mainly define two staged collaborative allocation strategies, which are the berth and yard collaborative allocation with two staged independent scheduling strategy (BYCA-TSIS) and berth and yard collaborative allocation with two staged coupling scheduling strategy (BYCA-TSCS). The model of the BYCA-TSIS and BYCA-TSCS may be based on the BYCA-IESO model of BYIS-SDTT or BYIS-ADTT. On the one hand, the BYIS-SDTT or BYIS-ADTT is to verify the feasibility, availability, and superiority of the BYCA-IESO model. On the other hand, the BYCA-TSIS and BYCA-TSCS provide the staged and lightweight solution to BYCA-IESO with low computational complexity in comparison to BYISSDTT or BYIS-ADTT under the same running constraints of quayside berth and storage yard. Figure 3 demonstrates the solving process of BYCA-TSIS and BYCA-TSCS from the perspective of contrast.

More importantly, from Figures 2 and3, it is easy to conclude the similarities and differences among BYISSDTT, BYIS-ADTT, BYCA-TSIS, and BYCA-TSCS. The optimization goals of the four tactics are all same that are just about the weighted sum of the total time consumption of calling liners and the total horizontal transferring distances of YTs. For one thing, whether the BYIS-SDTT or the BYISADTT both take integrated scheduling of berth allocation and yard assignment into account. The two consider the optimization goals in multiple associated dimensions of time and space simultaneously and determine the optimal berth and yard allocation scheme as an organic whole.

For another, as for BYCA-TSIS and BYCA-TSCS, the two are to determine the optimal berth allocation scheme firstly and then to determine the optimal yard allocation plan. In the first stage, both only consider minimizing the optimization objectives in terms of time costs for the berth allocation. In the second stage, they are only to optimize the horizontal transferring distances of YTs. From Figure 3, the differences between BYCA-TSIS and BYCA-TSCS can be seen in the dotted box. Although they both optimize berth allocation and yard distribution, respectively, the BYCA-TSIS only focuses on the berth allocation problem in the first solution phase and does not consider the influence of berth optimization results on subsequent yard allocation. The influence is mainly in the aspect of the time costs. On the contrary, the BYCA-TSCS takes the yard allocation rules and constraints into account in the first solution stage while working out the berth allocation plan. Whether BYCA-TSIS or BYCA-TSCS, both are to determine the yard allocation plan in the time and space based on the foregoing berth scheme solved in the first stage. All four scheduling strategies provide different planning emphasis and scheduling paradigm for BYCA-IESO from the synergy service of processor cache and main memory by the abstraction and automation of computational logistics.

\section{Numerical Experiments}

We design and conduct several numerical experiments to demonstrate that the proposed model and recommended strategies are feasible in this section. The BYCA-IESO models are solved by the CPLEX 20.1.0 on a computer system with a central processing unit of Intel Core i9-10900 and a random access memory of 64.0 GB. Then, the effectiveness and superiority of the models are further illustrated by the comparison and analysis of the following experimental results.

The IBM CPLEX is a commercial optimization solver that performs well in solving the mathematic programming model. It can find an exact or high-quality solution to the model by its mixed integer optimizer, which is mainly based on exact algorithms. We use ILOG CPLEX Optimization Studio to implement and solve the proposed BYCA-IESO model with the tactics of BYIS-SDTT, BYIS-ADTT, BYCATSIS, and BYCA-TSCS.

5.1. Testing Instance Generation. We generate several testing instances for the numerical experiments to verify the feasibility, validity, and superiority of BYIS-SDTT and BYIS-ADTT. The target container terminal is located on the southeast coast of China. There are a quayside berth of 1800 meters and 150 blocks on storage yard. According to the field survey, there are seven production instances to be generated to test models and strategies. The lengths of 


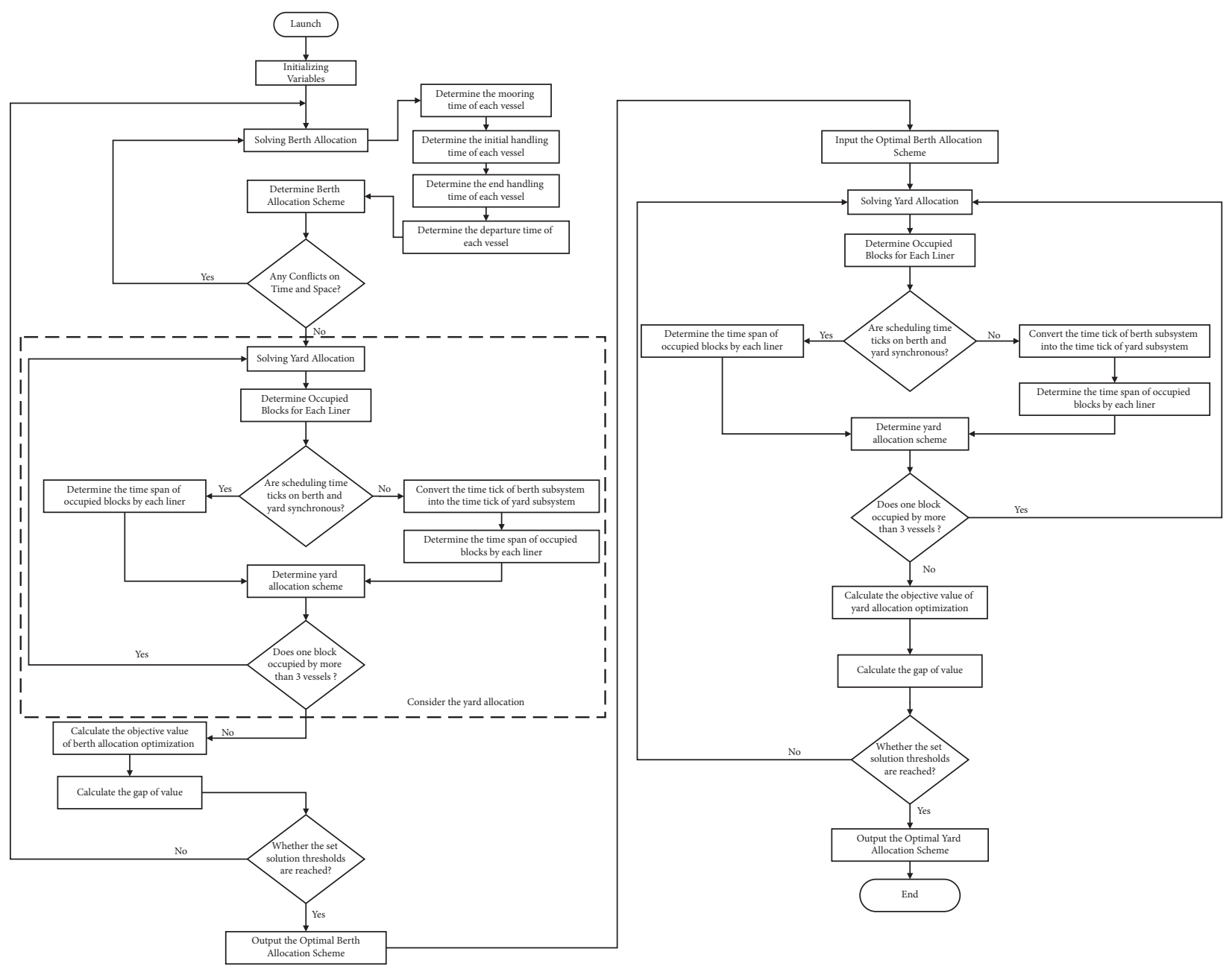

Figure 3: The solving process of staged scheduling strategies for BYCA-TSIS and BYCA-TSCS.

planning time cycle are all different which range from 60 hours to 168 hours. Considering that the handling time may exceed the planning horizon, we assume that the vessels exceeding the planning horizon must leave the terminal in 10 hours after the end of the planning cycle. For the number of vessels expected to arrive, it is determined based on the principle that the time interval between vessels arriving at the terminal is about three hours, which fully conforms to the production practice of the target terminal. The decision time tick in testing instances is not all synchronous. The block amount in four different types of yard zones that can be allocated for the vessels expected to arrive is different in each testing instance. It is determined by the number of the containers needed to be operated in the planning time cycle. The capacity of each block is 240 twenty-foot equivalent units (TEUs). We first estimate the minimum number of each type of blocks that meet the storage demand of vessels in the planning time cycle. Then, the number of blocks available for allocation in each testing instance is about $110 \%$ of the minimum requirements. More information of each testing instances is shown in Table 1. As shown in Table 1, some instances are appropriate for BYIS-SDTT, and the others are propitious to be solved by BYIS-ADTT.
The information about each vessel in instances is randomly generated according to the distribution law obtained from field research in the given terminal. Each vessel has a certain number of containers needed to be loaded and discharged in the terminal. Generally, the number of containers is related to the maximum designed capacity of the container ships. Different types of container vessel have different capacities. For the types of vessels, we randomly select vessels from common container vessels in the maritime market. The number proportion of different types of vessels and its loading and unloading container number is determined according to the key attributes of vessels in [49]. The containers of vessel have been classified into four types in the model. In addition to determining the total container amount of each vessel needed to be operated, the four types of container amount also need to be determined. Here, we generate it according to a certain proportion based on the total container amount of each vessel. The caveat is that the proportion of the four types of containers in the total number of containers that each ship needs to load and unload at the port is fixed. As for the proportion of four types of containers in this test instance, the heavy container quantity in each vessel is approximately $75 \%$, and the proportion of empty containers is about $25 \%$. The proportion of import containers in heavy containers or empty 
TABLE 1: The basic formation of each testing instance.

\begin{tabular}{|c|c|c|c|c|c|c|c|c|c|}
\hline \multirow{3}{*}{ Instances } & \multirow{3}{*}{ Liner quantity } & \multirow{3}{*}{ Planning cycle (hours) } & \multirow{3}{*}{ Berth length (meters) } & \multicolumn{2}{|c|}{$\begin{array}{l}\text { Decision time } \\
\text { tick (hours) }\end{array}$} & \multicolumn{4}{|c|}{$\begin{array}{l}\text { Blocks in yard that can be allocated } \\
\text { in the planning cycle }\end{array}$} \\
\hline & & & & \multirow{2}{*}{ Berth } & \multirow{2}{*}{ Yard } & \multicolumn{2}{|c|}{ Import zones } & \multicolumn{2}{|c|}{ Empty zones } \\
\hline & & & & & & Heavy & Empty & Heavy & Empty \\
\hline $\mathrm{I}$ & 20 & 60 & 1800 & 0.5 & 0.5 & 32 & 22 & 32 & 22 \\
\hline II & 25 & 72 & 1800 & 0.5 & 0.5 & 37 & 28 & 37 & 28 \\
\hline III & 30 & 84 & 1800 & 0.25 & 2 & 39 & 33 & 39 & 33 \\
\hline IV & 35 & 100 & 1800 & 0.25 & 2 & 47 & 39 & 47 & 39 \\
\hline $\mathrm{V}$ & 40 & 120 & 1800 & 0.5 & 2 & 60 & 45 & 60 & 45 \\
\hline VI & 45 & 141 & 1800 & $1 / 3$ & 3 & 65 & 50 & 65 & 50 \\
\hline VII & 50 & 168 & 1800 & 1 & 3 & 70 & 55 & 70 & 55 \\
\hline
\end{tabular}

TABLE 2: The container number and minimum block quantity requirement of each instance.

\begin{tabular}{|c|c|c|c|c|c|c|c|c|}
\hline \multirow{3}{*}{ Instance } & \multicolumn{4}{|c|}{ Container quantity } & \multicolumn{4}{|c|}{ Minimum block quantity requirements } \\
\hline & \multicolumn{2}{|c|}{ Import container } & \multicolumn{2}{|c|}{ Export container } & \multicolumn{2}{|c|}{ Import zones } & \multicolumn{2}{|c|}{ Export zones } \\
\hline & Heavy & Empty & Heavy & Empty & Heavy & Empty & Heavy & Empty \\
\hline $\mathrm{I}$ & 4383 & 1465 & 4383 & 1465 & 27 & 20 & 27 & 20 \\
\hline II & 4860 & 1620 & 4860 & 1620 & 33 & 25 & 33 & 25 \\
\hline III & 5127 & 1715 & 5127 & 1715 & 35 & 30 & 35 & 30 \\
\hline IV & 5873 & 1964 & 5873 & 1964 & 42 & 35 & 42 & 35 \\
\hline V & 8048 & 2685 & 8048 & 2685 & 51 & 40 & 51 & 40 \\
\hline VI & 7871 & 2624 & 7871 & 2624 & 58 & 45 & 58 & 45 \\
\hline VII & 8262 & 2756 & 8262 & 2756 & 57 & 50 & 57 & 50 \\
\hline
\end{tabular}

containers is about $50 \%$, same as the export containers. After generating the container number of each liner, we can calculate the minimum block quantity requirements of the total containers' storage on each instance, which can be seen in Table 2.

The running time related to calling liner is all randomly generated, except the operational time of each vessel which is determined by the number of the quay cranes assigned to it. For the quay crane quantity assigned to the vessel, we arrange one every 50 meters according to the length of vessel. The operating efficiency of quay crane is 26 TEU per hour. Thus, we can calculate the handling time of every vessel based on their length and total container number needed to be operated.

For each vessel, their export containers must be prestored in the export yard zones in advance. The pre-storage time is between 6 and 18 hours. Similar to export containers, the import containers are usually retained in the import yard zones for a period of time. The maximum retention time of import containers in the import container storage yard is also 18 hours and the minimum time is 6 hours. If the handling time of vessels exceeds the planning horizon, the retention time of their import container is 6 hours. In this paper, the arrival time, pre-storage time, and retention time of each vessel are all generated randomly by Microsoft Excel 2019.

Figure 4 shows the plane layout of quayside berth and yard zones in this test instance. The quayside berth is continuous, and its total length is 1800 meters, which is divided 120 segments evenly. Meanwhile, the water depth along the wharf apron reaches up to 18.5 meters. That is to say, the calling container ships can moor at any segments of the quayside berth, and the berth allocation has no additional physical restrictions. In terms of space layout of storage yard, there are four main zones: the import heavy container zone, import empty container zone, export empty container zone, and export heavy container zone. The heavy container zone of the yard is in front of the empty container zone. That is, the heavy container zone is closer to the terminal quayside, which is consistent with the actual layout of container terminals in the vast majority of cases. Each zone has two main subareas to store import containers and export containers, respectively. That four areas all have a certain number of blocks. The heavy area has 70 blocks, and empty container area has 55 blocks. Each block can store up to 240 TEUs. At the beginning of the planning cycle, there are no containers stored in all blocks.

5.2. Numerical Experimentation. Based on the above testing instances, we expatiate on the solving process of the BYCA-IESO models in this section by the model design procedure, the parameter setting, and the statistical information of each testing instance in the CPLEX Optimization Studio. We use its integrated development environment (IDE), optimization programming language (OPL), and the CPLEX Optimization engine to implement, debug, test, and solve the planning model. It mainly covers four steps to solve the model with the IDE, which are creating a project and loading the model files, compiling the model with OPL, importing an optional setting file in the project, and running the model file to acquire the solution.

It is worth mentioning the parameter setting of CPLEX Optimization engine. Most of the configuration parameters are default. We only change some key parameter settings. 


\begin{tabular}{|c|c|c|c|c|}
\hline block51 & block52 & block53 & block54 & block 55 \\
\hline \multicolumn{5}{|c|}{ (n...... } \\
\hline block16 & block17 & block18 & block19 & block 20 \\
\hline block11 & block12 & block13 & block14 & block15 \\
\hline block6 & block7 & block8 & block9 & block10 \\
\hline block1 & block2 & block3 & block4 & block5 \\
\hline \multicolumn{5}{|c|}{ The export empty container zones } \\
\hline block65 & block67 & block68 & block69 & block70 \\
\hline \multicolumn{5}{|c|}{$\ldots \ldots \ldots$} \\
\hline block16 & block17 & block18 & block19 & block 20 \\
\hline block11 & block12 & block13 & block14 & block15 \\
\hline block6 & block7 & block8 & block9 & block10 \\
\hline block1 & block2 & block3 & block4 & block5 \\
\hline
\end{tabular}

\begin{tabular}{|c|c|c|c|c|}
\hline block51 & block52 & block53 & block54 & block 55 \\
\hline \multicolumn{5}{|c|}{......... } \\
\hline block16 & block17 & block18 & block19 & block 20 \\
\hline block11 & block12 & block13 & block14 & block15 \\
\hline block6 & block7 & block8 & block9 & block10 \\
\hline block1 & block2 & block3 & block 4 & block5 \\
\hline \multicolumn{5}{|c|}{ The export empty container zones } \\
\hline block65 & block67 & block68 & block69 & block70 \\
\hline block16 & block17 & block18 & block19 & block 20 \\
\hline block11 & block12 & block13 & block14 & block15 \\
\hline block6 & block7 & block8 & block9 & block10 \\
\hline block1 & block2 & block3 & block4 & block5 \\
\hline
\end{tabular}

Berth

FIGURE 4: The plane layout of quayside berth and storage yard for testing instances.

The number of parallel threads that CPLEX optimizer can utilize is set to 16 because of the memory limitation of the workstation. The generated nodes by the CPLEX Optimizer during solving problem are stored in the memory allocated for working storage. When the node set is larger than the memory available for working storage, CPLEX will output resulting node files in the main memory or compress the nodes files and dump the peripheral storage disk if necessary. By default, the amount of memory allocated to the workspace is $2048 \mathrm{MB}$, and the resulting node files is stored in memory in compressed form. In our experiments, we allocate $61440 \mathrm{MB}$ to the working storage; moreover, when the working storage is not enough, the node files will be transferred to disk. The problem scales of the BYCA-IESO models are enormous, which are solved by the CPLEX, so the mixed integer programming (MIP) variable selection strategy is set to the strong branching strategy to accelerate the solution process. In the meantime, we also change the global time for limiting the cost of solution time.

To make the CPLEX run better, we also customize some key parameter settings while solving the testing instances. These settings are mainly the MIP variable selection strategy, MIP priority order switch, and the node pre-solve switch. Above all, the MIP node selection strategy is set to bestestimate strategy. Secondly, for the MIP priority order switch, we set to not use the priority order. Lastly, we set MIP priority order switch to force pre-solve at nodes.

Tables 3-7 record the key statistic information when solving instances based on the BYIS-SDTT, BYIS-ADTT,
BYCA-TSIS, and BYCA-TSCS. From these tables, we can understand the problem scales of the instances by the core indicators, which cover objective function value (OFV) of the solution, constraint number, variable number, and nonzero coefficient number when solving different instances with different strategies by CPLEX. The total iterations of each instance with different strategies are also shown in the tables. CPLEX will record the integer solution it finds which is stored in solution pool. The number of solutions in the pool and average value of the objective function are shown in the last column of the tables. It is worth mentioning that the BYCA-TSIS and BYCA-TSCS are solving the BYCA-IESO model in stages whose core indicators are illustrated by the two separate tables.

Figure 5 shows the convergence conditions of each instance with the strategy of BYIS-SDTT or BYIS-ADTT. From Figure 5, it is concluded that the convergence rate is relatively fast in the initial phase after CPLEX has found the first integer solution. At the same time, the convergence rate becomes relatively slow in the later stage of the optimal solution. It is an advantageous characteristic for the solution to BYCA-IESO, especially for the intelligent decision support for CTHS in practice.

5.3. Experimental Results and Performance Comparison. In this section, we introduce and analyze the experimental results about CPLEX solving the testing instances. We, 
TABLE 3: The solving statistical information with BYIS-SDTT or BYIS-ADTT by CPLEX.

\begin{tabular}{lcccccccc}
\hline \multirow{2}{*}{ Instance } & \multirow{2}{*}{ OFV } & \multirow{2}{*}{ Constraints } & \multicolumn{2}{c}{ Variables } & Nonzero coefficients & Iterations & \multicolumn{2}{c}{ Solution pool } \\
Count & Average OFV \\
\hline I & 0.6530 & 757368 & 370520 & 140 & 2849480 & 3674829 & 82 & 0.6565 \\
II & 0.7793 & 1290500 & 634450 & 175 & 4755425 & 3563154 & 84 & 0.7855 \\
III & 1.6593 & 564954 & 269670 & 210 & 2291490 & 6078222 & 77 & 1.6623 \\
IV & 1.8886 & 876583 & 421575 & 245 & 3417820 & 5136286 & 52 & 1.8924 \\
V & 1.2614 & 1311855 & 645520 & 280 & 5022640 & 4898870 & 129 & 1.2691 \\
VI & 2.0680 & 1302865 & 632835 & 315 & 5019255 & 1721675 & 57 & 2.0787 \\
VII & 0.8210 & 720775 & 363750 & 350 & 3148600 & 3497840 & 389 & 2.721 \\
\hline
\end{tabular}

TABLE 4: The solving statistical information with BYCA-TSIS for the first stage by CPLEX.

\begin{tabular}{lccccccc}
\hline \multirow{2}{*}{ Instance } & \multirow{2}{*}{ OFV } & \multirow{2}{*}{ Constraints } & \multicolumn{2}{c}{ Variables } & Nonzero coefficients & Iterations & \multicolumn{2}{c}{ Solution pool } \\
Count & Mean OFV \\
\hline I & 0.6338 & 22160 & 9800 & 140 & 335240 & 2849 & 14 \\
II & 0.7537 & 30600 & 13700 & 175 & 426425 & 3463 & 1.4841 \\
III & 1.6313 & 65880 & 31020 & 210 & 584760 & 3658 & 1 \\
IV & 1.8563 & 86520 & 41020 & 245 & 706545 & 3301 & 1 \\
V & 1.2188 & 66720 & 30800 & 280 & 727280 & 46493 & 3 \\
VI & 2.0100 & 112770 & 53505 & 315 & 912690 & 3731 & 1.6313 \\
VII & 0.7631 & 66300 & 29950 & 350 & 866850 & 99683 & 1.2369 \\
\hline
\end{tabular}

TABLE 5: The solving statistical information with BYCA-TSIS for the second stage by CPLEX.

\begin{tabular}{|c|c|c|c|c|c|c|c|c|}
\hline \multirow{2}{*}{ Instance } & \multirow{2}{*}{ OFV } & \multirow{2}{*}{ Constraints } & \multicolumn{2}{|c|}{ Variables } & \multirow{2}{*}{ Nonzero coefficients } & \multirow{2}{*}{ Iterations } & \multicolumn{2}{|c|}{ Solution pool } \\
\hline & & & Binary & Integer & & & Count & Mean OFV \\
\hline I & 0.0242 & 735208 & 360720 & - & 1797120 & 51 & 4 & 0.032 \\
\hline II & 0.0302 & 1259900 & 620750 & - & 3094000 & 125 & 2 & 0.0413 \\
\hline III & 0.0419 & 499074 & 238650 & - & 1655370 & 167 & 4 & 0.0572 \\
\hline IV & 0.0483 & 790063 & 380555 & - & 2642395 & 173 & 4 & 0.0650 \\
\hline V & 0.0477 & 1245135 & 614720 & - & 4249600 & 199 & 3 & 0.0615 \\
\hline VI & 0.0579 & 1190095 & 579330 & - & 4018275 & 214 & 3 & 0.0726 \\
\hline VII & 0.0621 & 654475 & 333800 & - & 2266450 & 78 & 3 & 0.0769 \\
\hline
\end{tabular}

TABLE 6: The solving statistical information with BYCA-TSCS for the first stage by CPLEX.

\begin{tabular}{|c|c|c|c|c|c|c|c|c|}
\hline \multirow{2}{*}{ Instance } & \multirow{2}{*}{ OFV } & \multirow{2}{*}{ Constraints } & \multicolumn{2}{|c|}{ Variables } & \multirow{2}{*}{ Nonzero coefficients } & \multirow{2}{*}{ Iterations } & \multicolumn{2}{|c|}{ Solution pool } \\
\hline & & & Binary & Integer & & & Count & Mean OFV \\
\hline I & 0.6338 & 757368 & 370520 & 140 & 2849480 & 33138 & 1 & 0.6338 \\
\hline II & 0.7537 & 1290500 & 634450 & 175 & 4755425 & 68273 & 1 & 0.7538 \\
\hline III & 1.6313 & 564954 & 269670 & 210 & 2291490 & 17917 & 1 & 1.6313 \\
\hline IV & 1.8563 & 876583 & 421575 & 245 & 3417820 & 22256 & 1 & 1.8563 \\
\hline $\mathrm{V}$ & 1.2188 & 1311855 & 645520 & 280 & 5022640 & 159690 & 6 & 1.2316 \\
\hline VI & 2.0100 & 1302865 & 632835 & 315 & 5019255 & 38752 & 1 & 2.0100 \\
\hline VII & 0.7631 & 720775 & 363750 & 350 & 3148600 & 95168 & 8 & 0.7718 \\
\hline
\end{tabular}

TABLE 7: The solving statistical information with BYCA-TSCS for the second stage by CPLEX.

\begin{tabular}{lccccccc}
\hline \multirow{2}{*}{ Instance } & \multirow{2}{*}{ OFV } & \multirow{2}{*}{ Constraints } & \multicolumn{2}{c}{ Variables } & Nonzero coefficients & Iterations & \multicolumn{2}{c}{ Solution pool } \\
Count & Mean OFV \\
\hline I & 0.0247 & 735208 & 360720 & - & 1797120 & 49 & 4 \\
II & 0.0309 & 1259900 & 620750 & - & 3094000 & 112 & 2 \\
III & 0.0358 & 499074 & 238650 & - & 1655370 & 139 & 3 \\
IV & 0.0406 & 790063 & 380555 & - & 2642395 & 145 & 4 \\
V & 0.0574 & 1245135 & 614720 & - & 4249600 & 198 & 3 \\
VI & 0.0592 & 1190095 & 579330 & - & 4018275 & 207 & 3 \\
VII & 0.0638 & 654475 & 333800 & - & 2266450 & 78 & 0.0453 \\
\hline
\end{tabular}



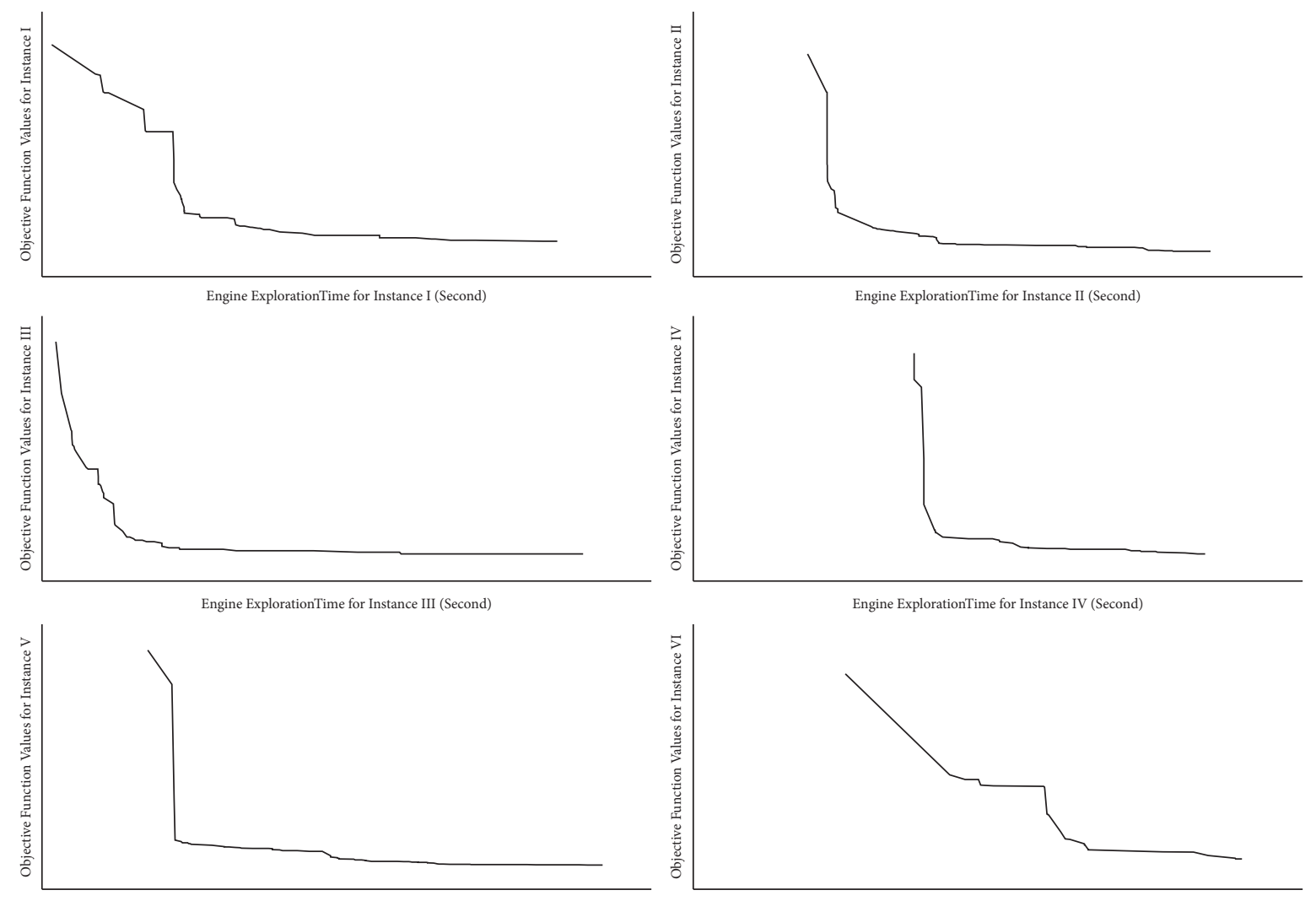

FIgURE 5: The convergence condition when CPLEX solves each instance.

respectively, use all testing instances to verify the feasibility of the four scheduling strategies. We first analyze the result of the BYIS-SDTT or BYIS-ADTT to verify their feasibility and availability. Then, we will analyze the effectiveness of BYIS-SDTT or BYIS-ADTT by comparing them with the results of BYCA-TSIS and BYCA-TSCS.

We mainly analyze the experimental results of the BYISSDTT and BYIS-ADTT. Compared with the result of BYCATSIS and BYCA-TSCS, the problem scale is much larger, which can be seen from Tables 3-7. CPLEX usually takes quite a long time to find the optimal solution, and it may take up to a week or more. This is unacceptable in terminal practice. Therefore, we set the parameters of global time limit for solver to be a maximum time for CPLEX. It means that the CPLEX optimizer will output the currently found integer solution after reaching the maximum time. The set of global time limit is different for each testing instance. The longest is 12 hours, and the shortest is 3 hours, which are shown in Table 8. Furthermore, the gap of OFV is also shown in Table 8 about the output solutions. The gap of all solutions did not reach the default gap. However, the gap about most testing instances is under $4 \%$. In consideration of the problem scale of instance VII, the gap of its solution is $7.28 \%$ which is the maximum value among all testing instances. But we can still consider that this is a high-quality solution. As a result, the CPLEX can find the high-quality solutions for all testing instances.

The objective functions of the BYIS-SDTT and BYISADTT that CPELX Optimizer solves have been normalized. The actual value needs to be calculated for the analysis of the solution to BYIS-SDTT and BYIS-ADTT. Therefore, we compute the total time consumption for liners and the total transferring distances of YTs according to the solution of BYIS-SDTT and BYIS-ADTT. The OFV of each instance is shown in Table 3.

The OFV embodies the multiobjective optimization, and it consists of the total time consumption for liners and the total transferring distances of YTs that have been shown in Table 8. It is noticeable that the maximum value of the total consumption time for liners is the testing instance VII for its scale is the biggest. However, the maximum value of the total transferring distances of YTs is the testing instance VI. The YT in instance VI travels 15.2 kilometers more than the YT in instance VII. This is a very unexpected and reasonable result of the experiment, and it gives us some important lessons for the running of CTHS.

There are several different elements that consist of the total time consumption for liners and the total horizontal transferring distances of the YT, respectively. The values of these elements for each testing instance are shown in Table 9. In the time consumption, the time of waiting for berth is the minimum compared to other two parts. The BYIS-SDTT and BYIS-ADTT perform well in meeting berthing demands of vessels expected to arrive in planning cycle. For the horizontal transferring distances, it is roughly proportional to the requirements of blocks in each testing instance. The horizontal transferring distances to the empty container zones in instance VI are longer than those in instance VII, although the minimum demand of empty container blocks 
TABLE 8: High-quality satisfactory solutions obtained by CPLEX solver.

\begin{tabular}{lccccc}
\hline Instance & Liner quantity & Total consumption time (hours) & $\begin{array}{c}\text { Total transferring distances } \\
\text { (kilometer) }\end{array}$ & $\begin{array}{c}\text { Global time limit for solver } \\
\text { (hours) }\end{array}$ & $\begin{array}{c}\text { OFV gap } \\
(\%)\end{array}$ \\
\hline I & 20 & 169 & 30.77 & 5.0 & 2.95 \\
II & 25 & 201 & 40.82 & 5.0 & 3.21 \\
III & 30 & 217.5 & 44.81 & 10.0 & 7.0 \\
IV & 35 & 247.5 & 51.825 & 11.5 & 1.69 \\
V & 40 & 328 & 59.24 & 3.0 & 3.68 \\
VI & 45 & 357.34 & 92.845 & 7.0 & 7.0 \\
VII & 50 & 412 & 77.645 & 12.0 & 7.28 \\
\hline
\end{tabular}

TABLE 9: The components of objective function values for BYIS-SDTT and BYIS-ADTT.

\begin{tabular}{|c|c|c|c|c|c|c|c|}
\hline \multirow{3}{*}{ Instance } & \multicolumn{3}{|c|}{ Time consumption (hours) } & \multicolumn{4}{|c|}{ Horizontal transferring distances (kilometer) } \\
\hline & \multirow[t]{2}{*}{ Waiting for berth } & \multirow[t]{2}{*}{ Berthing time } & \multirow[t]{2}{*}{ Handling time } & \multicolumn{2}{|c|}{$\begin{array}{l}\text { Import container } \\
\text { zone }\end{array}$} & \multicolumn{2}{|c|}{$\begin{array}{c}\text { Export container } \\
\text { zone }\end{array}$} \\
\hline & & & & Heavy & Empty & Heavy & Empty \\
\hline I & 0 & 94.5 & 74.5 & 6.455 & 8.720 & 6.555 & 9.040 \\
\hline II & 0 & 113 & 88 & 9.315 & 8.260 & 10.535 & 12.710 \\
\hline III & 0 & 131.25 & 86.25 & 9.005 & 13.185 & 8.565 & 14.055 \\
\hline IV & 0 & 150 & 97.5 & 7.880 & 13.545 & 12.920 & 17.480 \\
\hline $\mathrm{V}$ & 2.5 & 182 & 142 & 10.980 & 16.770 & 12.790 & 18.700 \\
\hline VI & 0 & 223.67 & 133.67 & 24.650 & 27.700 & 18.085 & 22.410 \\
\hline VII & 6 & 253 & 153 & 18.135 & 26.030 & 12.120 & 21.360 \\
\hline
\end{tabular}

in instance VI is smaller than that in instance VII. This is a very interesting result. Now, further analysis of the obtained high-quality satisfactory solution is as follows.

All calling liners can finish handling operations and leave the terminal in the given planning cycle for the berth allocation scheme in all testing instances. The situation that the vessel needs to wait for a period of time to moor in the terminal only occurs in two instances. Moreover, the number of the waiting vessel is one. The waiting time for the berth is no more than 7 hours which have been shown in Table 9. The berth assigned to the arriving container ship for instance III, instance IV, instance VI, and instance VII is demonstrated in Figure 6, respectively, and the squares of different colors represent the calling liners with the different ship types.

In the meantime, Table 10 illustrates the block sequence numbers that indicate the occupied yard resources in the each instance. For the import heavy container zones, instance VI occupies the largest number of yard areas, which reaches up to 25 blocks. In striking contrast, instance I only utilizes 10 blocks. For the import empty container zones, instance VI holds up the largest number of yard areas, which has also reached 21 blocks. By contrast, instance I only takes up 8 blocks. For the export heavy container zones, instance VI occupies the largest number of yard areas, which has been up to 21 blocks. In sharp contrast, instance I only utilizes 9 blocks. For the export empty container zone, instance VI put the largest number of yard areas to use, which reaches 17 blocks. By a huge margin, instance I only uses 8 blocks. Consequently, instance VI employs the largest blocks in different types of container zones, and it interprets the expected requirements of yard resources for the rolling plan and smooth running of CTHS as well.
In addition, Figure 7 shows the occupation of the blocks in different container zones by vessels in all testing instances. From Figure 7, we can know that not all blocks are occupied by calling liners. Only parts of them are allocated and utilized to store the containers. At the same time, the number of vessels that occupy the same block varies from 1 to 7 , which has been illustrated by Figure 7 as well. By observing Figures 6 and7 simultaneously, we can see the features that the running of CTHS has obvious spatial locality and temporal locality, which is highly similar to the operation of computer systems [50]. It also proves the feasibility and credibility of modeling and optimizing complex logistics hub by computational logistics from another aspect.

Finally, the total time consumption of liners and the horizontal transferring distances of the YT can be obtained by BYIS-SDTT and BYIS-ADTT and BYCA-TSIS and BYCA-TSCS from Table 11. The total time consumption by BYIS-SDTT or BYIS-ADTT is larger than that of BYCA-TSIS and BYCA-TSCS in two instances. Actually, in the instances of $\mathrm{V}$ and VII, the differences lie in the waiting time for mooring. The total time consumption of BYCA-TSIS and BYCA-TSCS about those two instances is just five hours or an hour and a half shorter than BYIS-SDTT or BYIS-ADTT, but the horizontal transferring distances of the YTs are longer than those of BYIS-SDTT or BYIS-ADTT for the instances of V and VII, and the biggest differences among them reach up to 23.660 kilometers.

In fact, in the vast majority of cases, the horizontal transferring distances by BYIS-SDTT or BYIS-ADTT are much shorter than those by BYCA-TSIS and BYCA-TSCS except once. The shortened distances range from $1.810 \mathrm{ki}-$ lometers to 25.415 kilometers. According to the definition of container terminal oriented logistics generalized computational complexity [48], the logistics generalized computation 


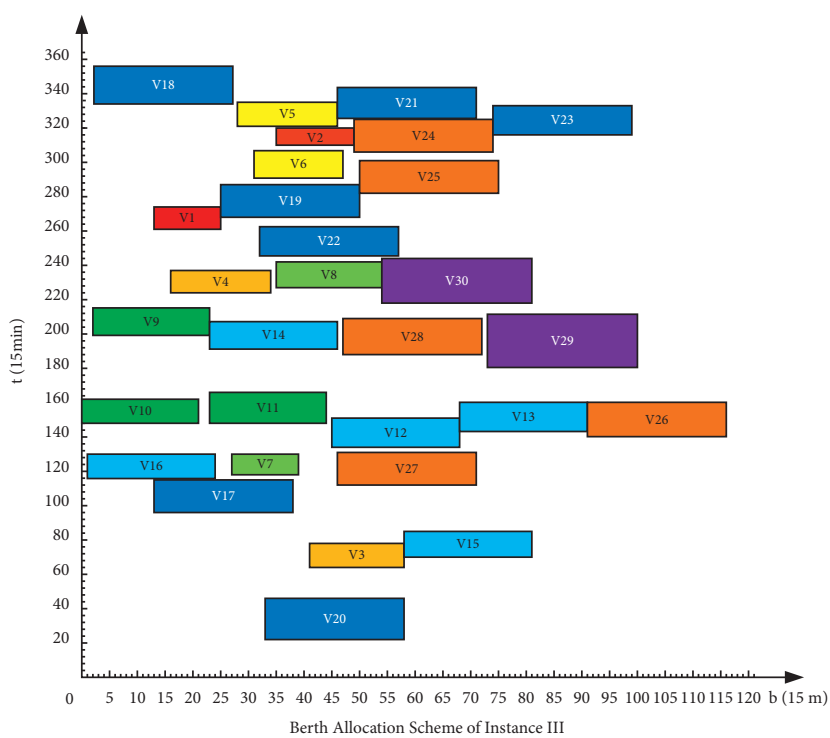

(a)

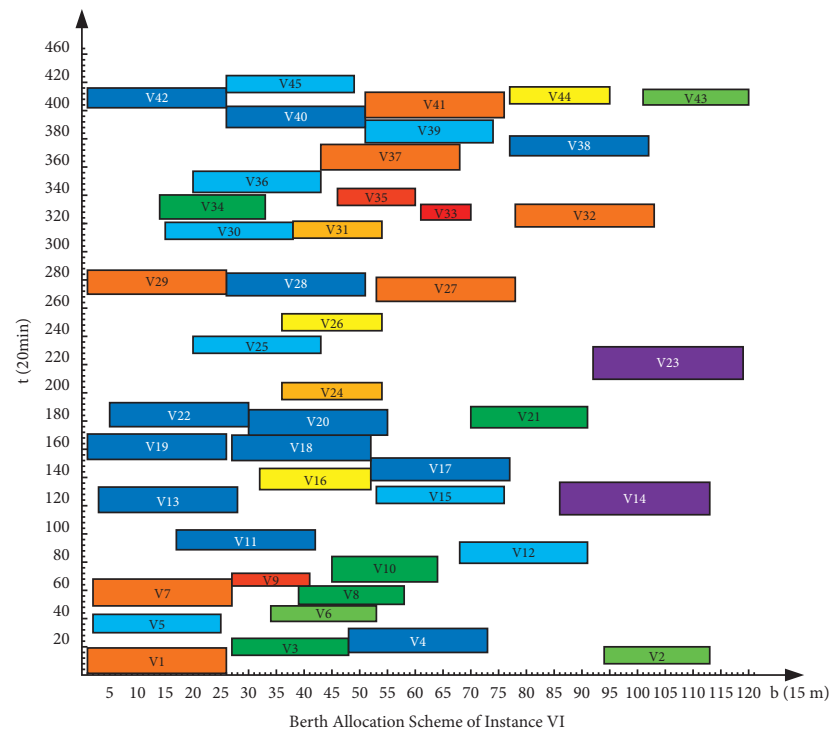

(c)

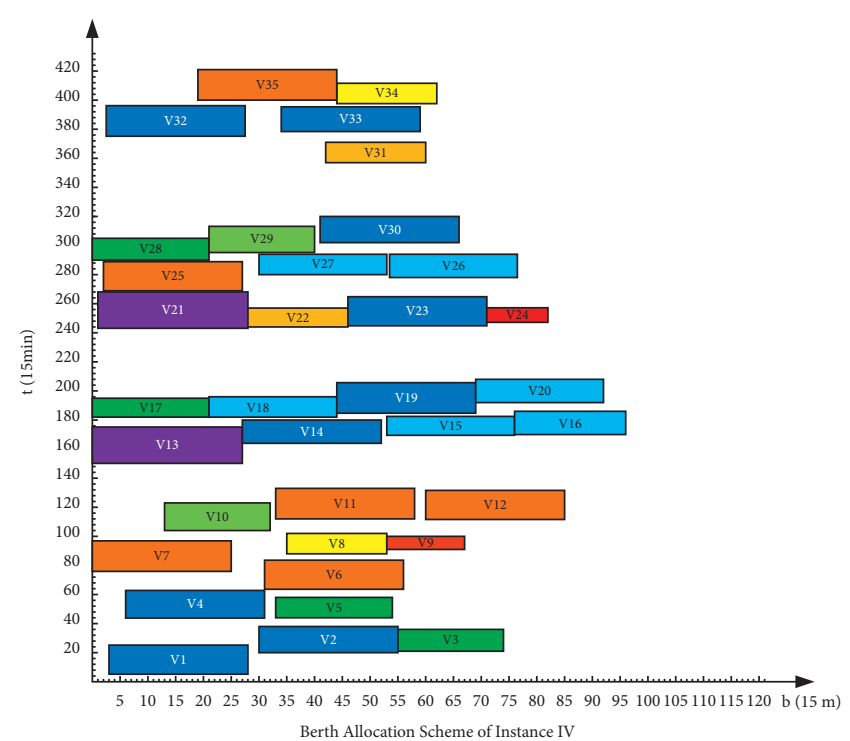

(b)

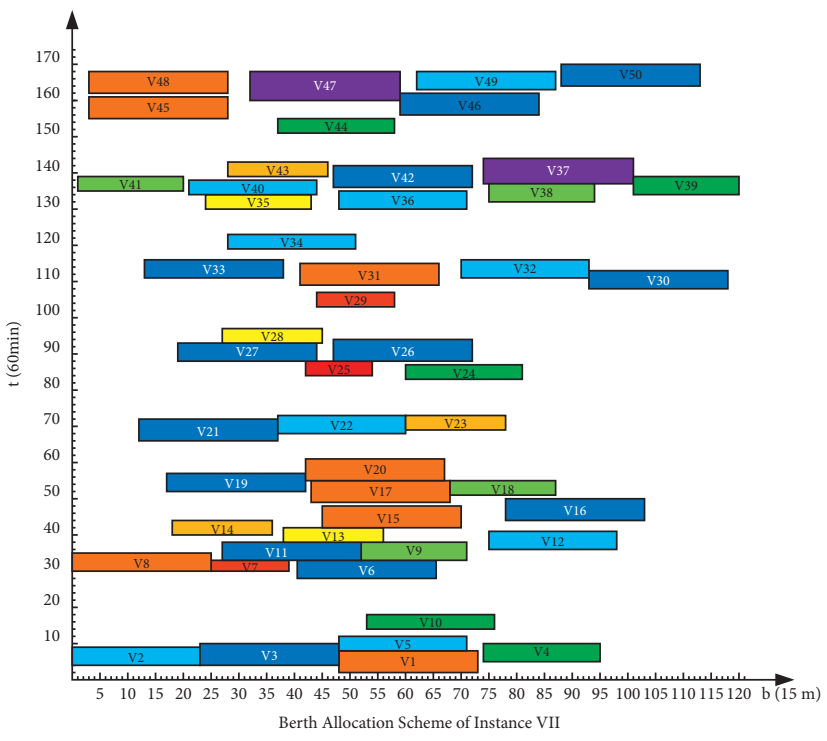

(d)

Figure 6: The berth allocation scheme about part of instances. (a) Berth allocation scheme of instance III. (b) Berth allocation scheme of instance IV. (c) Berth allocation scheme of instance VI. (d) Berth allocation scheme of instance VII.

communication complexity by BYIS-SDTT or BYIS-ADTT is superior to that with BYCA-TSIS and BYCA-TSCS on the condition that the logistics generalized computation space complexity for vessels is identical or similar among the above four allocation strategies. This is very beneficial for green port operation, reducing carbon emissions.

Nevertheless, the computation time for the testing instances by BYCA-TSIS or BYCA-TSCS is far less than that by BYIS-SDTT or BYIS-ADTT, which has been demonstrated by Table 12 . An important conclusion can be drawn from the contrast of Table 8 and Table 12. When the multiobjective optimization of BYCA-IESO with BYIS-SDTT or BYISADTT is split into the combination of the multiple singleobjective optimization problems by BYCA-TSIS or BYCATSCS, the BYCA-IESO models all obtain the theoretical optimal solutions on short notice. It provides tremendous convenience for the soft real-time intelligent decision support for BYCA-IESO, especially for BYCA-TSIS. In conclusion, the integrated tactics of BYIS-SDTT or BYIS-ADTT and the phased strategies of BYCA-TSIS or BYCA-TSCS provide the solutions to BYCA-IESO with the similar performances and different advantages.

5.4. Multiobjective Solution Pareto Analysis. The objective function in the BYIS-SDTT or BYIS-ADTT contains two main objectives to optimize; moreover, each objective has several subobjectives. It is essential to analyze the impact of subobjectives of those two main objectives. The objective about total time consumption for liners consists of three subobjectives, which are the time of waiting time for berth, the berthing time at the terminal, and the handling time. The 


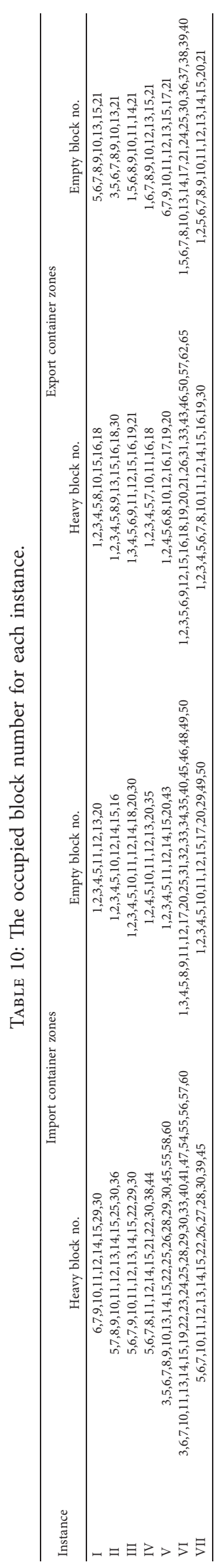



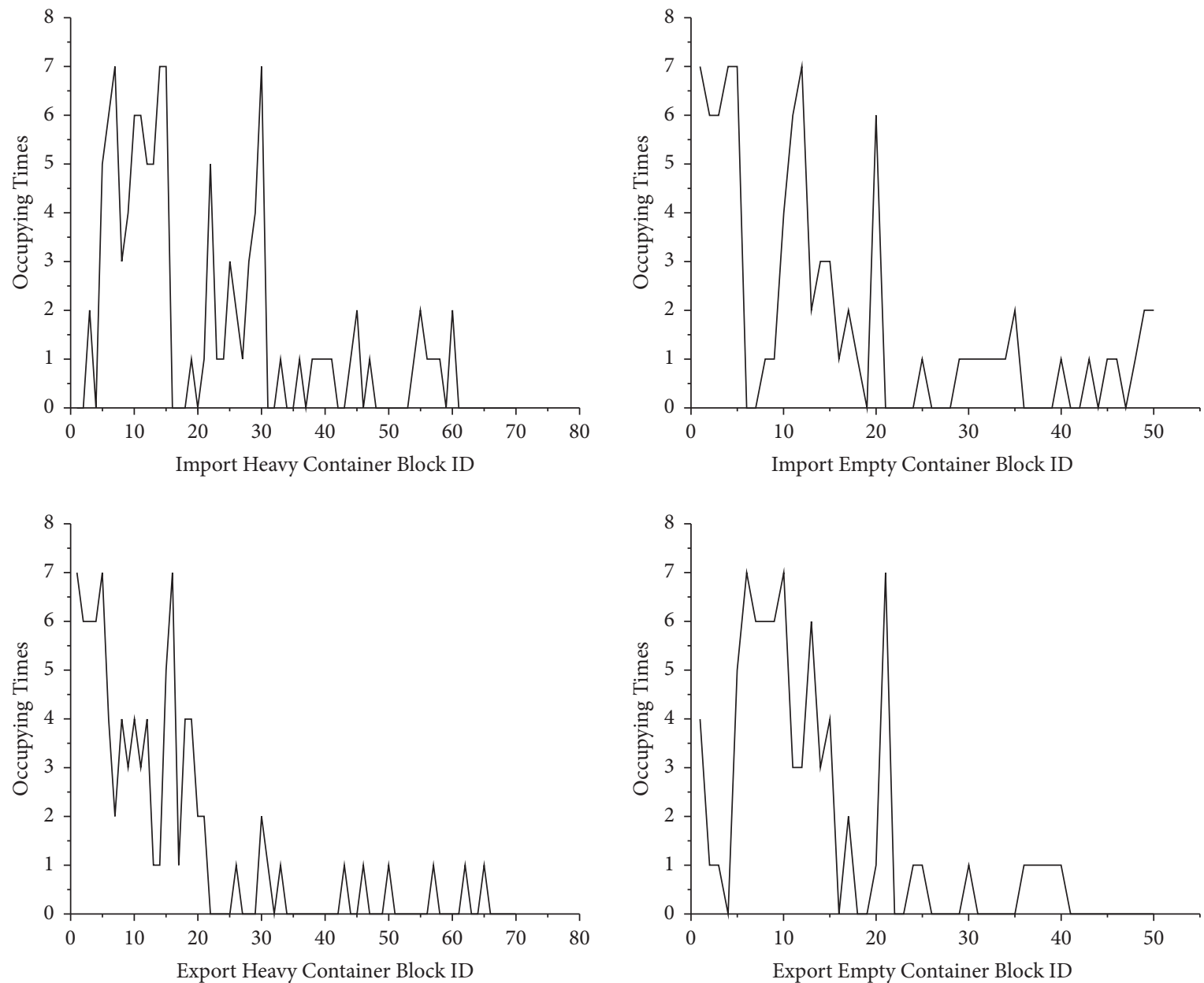

FIgURE 7: The number of vessels that occupy each block in four kinds of container zones.

TABLE 11: The objective function values for BYIS-SDTT, BYIS-ADTT, BYCA-TSIS, and BYCA-TSCS.

\begin{tabular}{|c|c|c|c|c|c|c|}
\hline \multirow{2}{*}{ Instance } & \multicolumn{3}{|c|}{ Total time consumption (hours) } & \multicolumn{3}{|c|}{ Horizontal transferring distances (kilometer) } \\
\hline & BYIS-SDTT or BYIS-ADTT & BYCA-TSIS & BYCA-TSCS & BYIS-SDTT or BYIS-ADTT & BYCA-TSIS & BYCA-TSCS \\
\hline I & 169 & 169 & 169 & 30.770 & 38.795 & 39.555 \\
\hline II & 201 & 201 & 201 & 40.820 & 48.365 & 49.400 \\
\hline III & 217.5 & 217.5 & 217.5 & 44.810 & 67.070 & 57.340 \\
\hline IV & 247.5 & 247.5 & 247.5 & 51.825 & 77.240 & 64.980 \\
\hline $\mathrm{V}$ & 326.5 & 325 & 325 & 59.240 & 76.335 & 82.480 \\
\hline VI & 357.34 & 357.34 & 357.34 & 92.845 & 92.570 & 94.655 \\
\hline VII & 412 & 407 & 407 & 77.645 & 99.360 & 101.305 \\
\hline
\end{tabular}

TABLE 12: Solving time by CPLEX for BYCA-TSIS and BYCA-TSCS.

\begin{tabular}{|c|c|c|c|c|}
\hline \multirow{3}{*}{ Instances } & \multicolumn{4}{|c|}{ Solving time by CPLEX } \\
\hline & \multicolumn{2}{|c|}{ Computing time for BYCA-TSIS (seconds) } & \multicolumn{2}{|c|}{ Computing time for BYCA-TSCS (seconds) } \\
\hline & First stage & Second stage & First stage & Second stage \\
\hline I & 0.55 & 0.59 & 31.23 & 0.59 \\
\hline II & 0.75 & 0.95 & 58.33 & 0.95 \\
\hline III & 0.91 & 0.44 & 14.28 & 0.45 \\
\hline IV & 1.20 & 0.67 & 26.61 & 0.66 \\
\hline $\mathrm{V}$ & 8.3 & 1.06 & 2267.56 & 1.06 \\
\hline VI & 1.72 & 0.97 & 44.59 & 0.95 \\
\hline VII & 102.48 & 0.58 & 547.66 & 0.61 \\
\hline
\end{tabular}




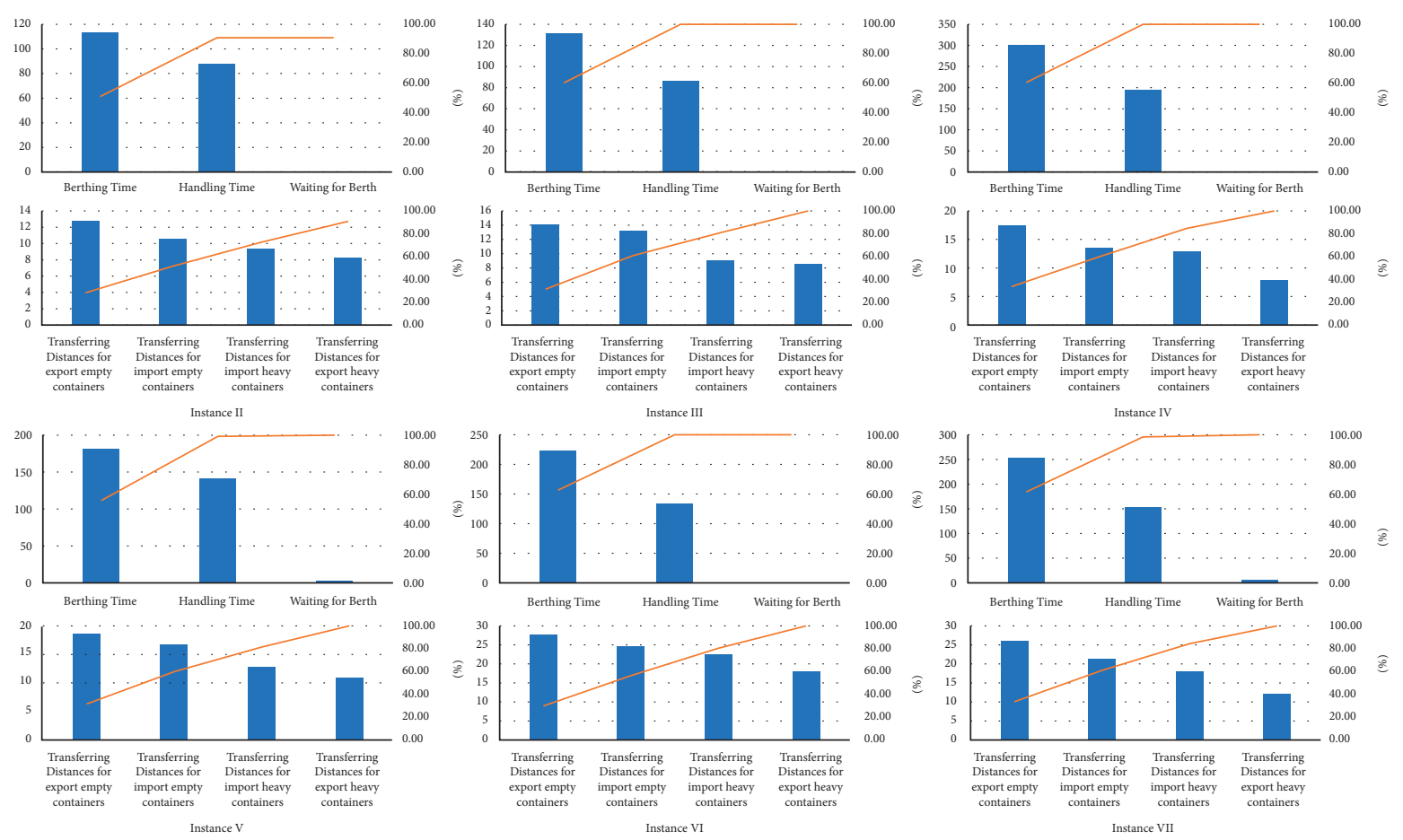

FIgURe 8: The Pareto analysis of each instance.

other objective contains the transferring distances to four different yard areas. The Pareto analysis may find the main indicators that influence the OFV.

Figure 8 shows the Pareto chart of OFV about 6 different testing instances by the BYIS-SDTT or BYISADTT. The left part for every instance in Figure 8 refers to the situations of time consumption components, and the right one refers to the transferring distances from quayside berth to different types of container zones. Consequently, it is concluded that the berthing time at the terminal in each instance accounts for 60 percent of the total time consumption. Now, we can classify the berthing time to be the main impact factor in the time optimization dimension. Meanwhile, the cumulative proportion of transferring distances from berth to empty zones is at around $60 \%$ steadily of the total travel distances of the YT. Therefore, the space optimization dimension is mainly affected by the transferring distances to import empty blocks and to export empty blocks. As a result, the working space allocation is vitally important for the running of CTHS.

\section{Conclusions}

In this paper, we design and implement the BYCA-IESO optimization by computational logistics. We propose a core set of scheduling policies (BYIS-SDTT or BYISADTT) by transferring and customizing the cooperative working principles of processor cache and main memory. The main difference between BYIS-SDTT and BYIS-ADTT is that the decision time ticks for quayside berth, and storage yard is synchronous or asynchronous when the terminal operators allocate berth and yard jointly. The
BYCA-IESO model is formulated based on the BYISSDTT or BYIS-ADTT. The objective of the BYCA-IESO model is to optimize the total time consumption for liners and the total transferring distances of the YT set. In order to better verify the availability and validity of the BYCAIESO model with BYIS-SDTT or BYIS-ADTT, we propose the multistage allocation tactics of BYCA-TSIS and BYCA-TSCS for BYCA-IESO. Several numerical experiments by CPLEX 20.1.0 are implemented and executed ultimately. Through the result analysis of testing instances with the BYIS-SDTT or BYIS-ADTT by comparing those with the BYCA-TSIS and BYCA-TSCS, it can be concluded that the proposed model and the corresponding allocation tactics can optimize the BYCA-IESO from the time and space dimensions; moreover, the addressed strategies have their own priorities and strengths. Most important of all, the BYCA-IESO is formulated and solved by a MIQP model whose scheduling policy is the fusion of the classical operational research and the original computational logistics essentially. It is the most important piece to the puzzle for the discussion of computational logistics.

\section{Data Availability}

The data used to support the findings of this study are included within the article.

\section{Conflicts of Interest}

The authors declare that they have no conflicts of interest. 


\section{Acknowledgments}

This research was funded by the Humanities and Social Science Programming Foundation of Ministry of Education of China (grant no. 19YJA630031) and the Scientific Research Foundation of Fujian University of Technology in China (grant no. GY-Z160125).

\section{References}

[1] Ç. Iris and J. S. L. Lam, "A review of energy efficiency in ports: operational strategies, technologies and energy management systems," Renewable and Sustainable Energy Reviews, vol. 112, pp. 170-182, 2019.

[2] Q. Meng, J. Weng, and L. Suyi, "Impact analysis of mega vessels on container terminal operations," Transportation Research Procedia, vol. 25, pp. 187-204, 2017.

[3] E. Musso and A. Sciomachen, "Impact of megaships on the performance of port container terminals," Maritime Economics \& Logistics, vol. 22, no. 3, pp. 432-445, 2020.

[4] T. G. Crainic, G. Perboli, and M. Rosano, "Simulation of intermodal freight transportation systems: a taxonomy," European Journal of Operational Research, vol. 270, no. 2, pp. 401-418, 2018.

[5] N. Nehme, B. Maddah, and I. A. Kaysi, "An integrated multiship crane allocation in Beirut Port container terminal," Operational Research, vol. 21, no. 3, pp. 1743-1761, 2021.

[6] B. Niu, Q. Liu, Z. Wang, L. Tan, and L. Li, "Multi-objective bacterial colony optimization algorithm for integrated container terminal scheduling problem," Natural Computing, vol. 20, no. 1, pp. 89-104, 2021.

[7] A. K. Y. Ng, K. Wong, E. C. Shou, and C. Jiang, "Geography and institutional change: insights from a container terminal operator," Maritime Economics \& Logistics, vol. 21, no. 3, pp. 334-352, 2019.

[8] Xi Xiang and C. Liu, “An expanded robust optimization approach for the berth allocation problem considering uncertain operation time," Omega, vol. 103, Article ID 102444, 2021.

[9] H. Hu, Mo Jiao, and Z. Lu, "Improved Benders decomposition for stochastic yard template planning in container terminals," Transportation Research Part C: Emerging Technologies, vol. 132, Article ID 103365, 2021.

[10] W. Guo, M. Ji, and H. Zhu, "Multi-period coordinated optimization on berth allocation and yard assignment in container terminals based on truck route," IEEE Access, vol. 9, pp. 83124-83136, 2021.

[11] A. Imai, E. Nishimura, and S. Papadimitriou, "The dynamic berth allocation problem for a container port," Transportation Research Part B: Methodological, vol. 35, no. 4, pp. 401-417, 2001.

[12] A. Imai, X. Sun, E. Nishimura, and S. Papadimitriou, "Berth allocation in a container port: using a continuous location space approach," Transportation Research Part B: Methodological, vol. 39, no. 3, pp. 199-221, 2005.

[13] B. Liu, Z.-C. Li, Y. Wang, and D. Sheng, "Short-term berth planning and ship scheduling for a busy seaport with channel restrictions," Transportation Research Part E: Logistics and Transportation Review, vol. 154, Article ID 102467, 2021.

[14] C. Zhang, J. Liu, Y.-w. Wan, K. G. Murty, and R. J. Linn, "Storage space allocation in container terminals," Transportation Research Part B: Methodological, vol. 37, no. 10, pp. 883-903, 2003.

[15] H. Yu, J. Ning, Yu Wang, J. He, and C. Tan, "Flexible yard management in container terminals for uncertain retrieving sequence," Ocean \& Coastal Management, vol. 212, Article ID 105794, 2021.

[16] Y. Tao and C.-Y. Lee, "Joint planning of berth and yard allocation in transshipment terminals using multi-cluster stacking strategy," Transportation Research Part E: Logistics and Transportation Review, vol. 83, pp. 34-50, 2015.

[17] Q. Zeng, Y. Feng, and Z. Chen, "Optimizing berth allocation and storage space in direct transshipment operations at container terminals," Maritime Economics \& Logistics, vol. 19, no. 3, pp. 474-503, 2017.

[18] E. Tadeu Bacalhau, L. Casacio, and A. Tavares de Azevedo, "New hybrid genetic algorithms to solve dynamic berth scheduling problem," Expert Systems with Applications, vol. 167, Article ID 114198, 2021.

[19] A. Imai, K. I. Nagaiwa, and C. W. Tat, "Efficient planning of berth allocation for container terminals in Asia," Journal of Advanced Transportation, vol. 31, no. 1, pp. 75-94, 1997.

[20] El Hammouti Issam, L. Azza, and El Merouani Mohamed, "Solving the hybrid berth allocation problem using a batinspired algorithm," in Proceedings of the 2018 4th International Conference on Optimization and Applications (ICOA), pp. 1-6, IEEE, Mohammedia, Morocco, April 2018.

[21] X. Xiang, C. Liu, and L. Miao, "Reactive strategy for discrete berth allocation and quay crane assignment problems under uncertainty," Computers \& Industrial Engineering, vol. 126, pp. 196-216, 2018.

[22] A. Agra and M. Oliveira, "MIP approaches for the integrated berth allocation and quay crane assignment and scheduling problem," European Journal of Operational Research, vol. 264, no. 1, pp. 138-148, 2018.

[23] F. Barbosa, C. Priscila, B. Rampazzo, and A. Yamakami, "The impact of time windows constraints on metaheuristics implementation. a study for the Discrete and Dynamic Berth Allocation Problem," , pp. 1-20, Applied Intelligence, 2021.

[24] A. Sheikholeslami, M. Mardani, E. Ayazi, and H. Arefkhani, "A dynamic and discrete berth allocation problem in container terminals considering tide effects," Iranian Journal of Science and Technology, Transactions of Civil Engineering, vol. 44, no. 1, pp. 369-376, 2020.

[25] J.-M. Yang, Z.-H. Hu, X.-Q. Ding, and J. X. Luo, “An integer linear programming model for continuous berth allocation problem,"vol. 4, pp. 74-77, in Proceedings of the 2009 International Conference on Information Management, Innovation Management and Industrial Engineering, vol. 4, IEEE, Xi'an, China, December 2009.

[26] C. Liu, Xi Xiang, and Li Zheng, "Two decision models for berth allocation problem under uncertainty considering service level," Flexible Services and Manufacturing Journal, vol. 29, no. 3, pp. 312-344, 2017.

[27] A. Malekahmadi, M. Alinaghian, S. R. Hejazi, and M. A. Assl Saidipour, "Integrated continuous berth scheduling and quay crane assignment and scheduling problem with time-dependent physical constraints in container terminals," Computers \& Industrial Engineering, vol. 147, Article ID 106672, 2020.

[28] E. Thanos, T. Toffolo, H. G. Santos, W. Vancroonenburg, and G. Vanden Berghe, "The tactical berth scheduling problem with time-variant specific quay crane assignments," Computers \& Industrial Engineering, vol. 155, Article ID 107168, 2021.

[29] T. Wang, Y. Du, D. Fang, and Z.-C. Li, "Berth allocation and quay crane assignment for the trade-off between service efficiency and operating cost considering carbon emission taxation," Transportation Science, vol. 54, no. 5, pp. 1307-1331, 2020. 
[30] O. Abou Kasm, D. Ali, and T. C. E. Cheng, "The integrated berth scheduling, quay crane assignment and scheduling problem. mathematical formulations and a case study," $A n$ nals of Operations Research, vol. 291, no. 1, pp. 435-461, 2020.

[31] C. Tan, J. He, and Y. Wang, "Berth allocation and quay crane assignment under uncertainties,"vol. 12, pp. 263-270, in Proceedings of the 27th ISTE International Conference on Transdisciplinary Engineering (ISTE2020), vol. 12, IOS Press, Warsaw, Poland, July 2020.

[32] A. Al-Refaie and H. Abedalqader, "Optimal berth allocation under regular and emergent vessel arrivals," Proceedings of the Institution of Mechanical Engineers - Part M: Journal of Engineering for the Maritime Environment, vol. 235, no. 2, pp. 642-656, 2021.

[33] A. Mahpour, A. Nazifi, and A. Mohammadian Amiri, "Development of optimization model to reduce unloading and loading time at berth in container ports," Iranian Journal of Science and Technology, Transactions of Civil Engineering, vol. 45, pp. 1-10, 2021.

[34] S.-W. Lin, C.-J. Ting, and K.-C. Wu, "Simulated annealing with different vessel assignment strategies for the continuous berth allocation problem," Flexible Services and Manufacturing Journal, vol. 30, no. 4, pp. 740-763, 2018.

[35] L. Zhen, E. P. Chew, and L. H. Lee, "An integrated model for berth template and yard template planning in transshipment hubs," Transportation Science, vol. 45, no. 4, pp. 483-504, 2011.

[36] M. L. Le and Y.-ying Zhao, "An integrated planning of berthing scheduling and sub-block Assignment based on optimal berth position," Systems Engineering, vol. 33, no. 1, pp. 152-158, 2015.

[37] K. Wang, L. Zhen, S. Wang, and G. Laporte, "Column generation for the integrated berth allocation, quay crane assignment, and yard assignment problem," Transportation Science, vol. 52, no. 4, pp. 812-834, 2018.

[38] X. Li and B. Jia, "The joint optimization between berth scheduling and yard assignment in a container port under uncertain environment," Modern Manufacturing Engineering, vol. 1, pp. 27-32, 2016.

[39] X. Han, L. Ju, L. Qian, and Z. Lu, "Dynamic decision making for the integrated scheduling of berth and yard resources at import/export container terminals," Journal of Shanghai Jiaotong University, vol. 53, no. 1, pp. 69-76, 2019.

[40] W. Guo, M. Ji, and H. Zhu, "Multi-period coordinated optimization on berth allocation and yard assignment in container terminals based on truck route," IEEE Access, vol. 9, p. 1, 2021.

[41] W. Guo, M. Ji, and H. Zhu, "Collaborative optimization of berth scheduling and yard storage in container terminals," Journal of Traffic and Transportation Engineering, vol. 7, pp. 56-70, 2019.

[42] E. Nishimura, "Yard and berth planning efficiency with estimated handling time," Maritime Business Review, vol. 5, no. 1, pp. 5-29, 2019.

[43] G. Jian, D.-H. Lee, and H. Hu, "Tactical berth and yard template design at container transshipment terminals. A column generation based approach," Transportation Research Part E: Logistics and Transportation Review, vol. 73, pp. 168-184, 2015.

[44] M. P. M. Hendriks, E. Lefeber, and J. T. Udding, "Simultaneous berth allocation and yard planning at tactical level," Spectrum, vol. 35, no. 2, pp. 441-456, 2013.

[45] H. L. Ma, S. H. Chung, H. K. Chan, and Li Cui, "An integrated model for berth and yard planning in container terminals with multi-continuous berth layout," Annals of Operations Research, vol. 273, no. 1-2, pp. 409-431, 2019.

[46] J. Xu, S. Wang, and Q. Xu, "Time-window based berth and yard allocation planning of container vessels," in Proceedings of the 15th Triennial International Conference (Ports 2019), pp. 633643, ASCE, Pittsburgh, Pennsylvania, September 2019.

[47] B. Li, "Container terminal logistics scheduling and decisionmaking within the conceptual framework of computational thinking," in Proceedings of the IEEE 54th Annual Conference on Decision and Control (CDC 2015), pp. 330-337, IEEE, Osaka, Japan, December 2015.

[48] B. Li, B. Sun, W. Yao, Y. He, and G. Song, "Container terminal oriented logistics generalized computational complexity," IEEE Access, vol. 7, pp. 94737-94756, 2019.

[49] B. Li, "Hierarchical, parallel, heterogeneous and reconfigurable computation model of container terminal handling system," Journal of Traffic and Transportation Engineering, vol. 19, no. 2, pp. 136-155, April 2019.

[50] B. Li and G. Song, "Computational logistics for container terminal logistics hubs based on computational lens and computing principles," IEEE Access, vol. 8, pp. 194820-194835, 2020. 